Review

\title{
The Chemical Reactivity of Anthocyanins and Its Consequences in Food Science and Nutrition
}

\author{
Olivier Dangles * (1) and Julie-Anne Fenger \\ University of Avignon, INRA, UMR408, 84000 Avignon, France; julie-anne.fenger@univ-avignon.fr \\ * Correspondence: olivier.dangles@univ-avignon.fr; Tel.: +33-490-144-446
}

Academic Editors: M. Monica Giusti and Gregory T. Sigurdson

Received: 6 July 2018; Accepted: 31 July 2018; Published: 7 August 2018

\begin{abstract}
Owing to their specific pyrylium nucleus (C-ring), anthocyanins express a much richer chemical reactivity than the other flavonoid classes. For instance, anthocyanins are weak diacids, hard and soft electrophiles, nucleophiles, prone to developing $\pi$-stacking interactions, and bind hard metal ions. They also display the usual chemical properties of polyphenols, such as electron donation and affinity for proteins. In this review, these properties are revisited through a variety of examples and discussed in relation to their consequences in food and in nutrition with an emphasis on the transformations occurring upon storage or thermal treatment and on the catabolism of anthocyanins in humans, which is of critical importance for interpreting their effects on health.
\end{abstract}

Keywords: anthocyanin; flavylium; chemistry; interactions

\section{Introduction}

Anthocyanins are usually represented by their flavylium cation, which is actually the sole chemical species in fairly acidic aqueous solution $(\mathrm{pH}<2)$. Under the $\mathrm{pH}$ conditions prevailing in plants, food and in the digestive tract (from $\mathrm{pH}=2$ to $\mathrm{pH}=8$ ), anthocyanins change to a mixture of colored and colorless forms in equilibrium through acid-base, water addition-elimination, and isomerization reactions [1,2]. Each chemical species displays specific characteristics (charge, electronic distribution, planarity, and shape) modulating its reactivity and interactions with plant or food components, such as the other phenolic compounds. This sophisticated chemistry must be understood to interpret the variety of colors expressed by anthocyanins and the color changes observed in time and to minimize the irreversible color loss signaling the chemical degradation of chromophores. The chemical reactivity of anthocyanins is also important to interpret their fate after ingestion and their effects on health, as anthocyanins may be consumed as a complex mixture of native forms, derivatives, and degradation products, which themselves can evolve in the digestive tract [3].

\section{The Basis of Anthocyanin Chemistry}

\subsection{Anthocyanins Are Weak Diacids}

Due to conjugation with the electron-withdrawing pyrylium ring, the phenolic $\mathrm{OH}$ groups of the flavylium ion at $\mathrm{C} 4^{\prime}, \mathrm{C} 5$, and $\mathrm{C} 7$ are fairly acidic $[1,2]$. In terms of structure-acidity relationships, it is clear that $\mathrm{C} 7-\mathrm{OH}$ is the most acidic group with a $\mathrm{p} K_{\mathrm{a} 1}$ of ca. 4 , i.e., $6 \mathrm{p} K_{\mathrm{a}}$ units below the phenol itself. The corresponding neutral quinonoid base (Figure 1) can thus be considered to be the prevailing tautomer. At higher $\mathrm{pH}$ levels, a second proton loss from $\mathrm{C} 4^{\prime}-\mathrm{OH}\left(\mathrm{p} K_{\mathrm{a} 2} \approx 7\right.$ for common anthocyanins) yields the anionic base with maximized electron delocalization over the three rings. Along this deprotonation sequence, the wavelength of maximal visible absorption typically shifts by $20-30 \mathrm{~nm}$ 
$\left(\mathrm{AH}^{+} \rightarrow \mathrm{A}\right)$, then by $50-60 \mathrm{~nm}\left(\mathrm{~A} \rightarrow \mathrm{A}^{-}\right)$(Figure 2$)$, and the corresponding color turns from red to purple-blue [4].

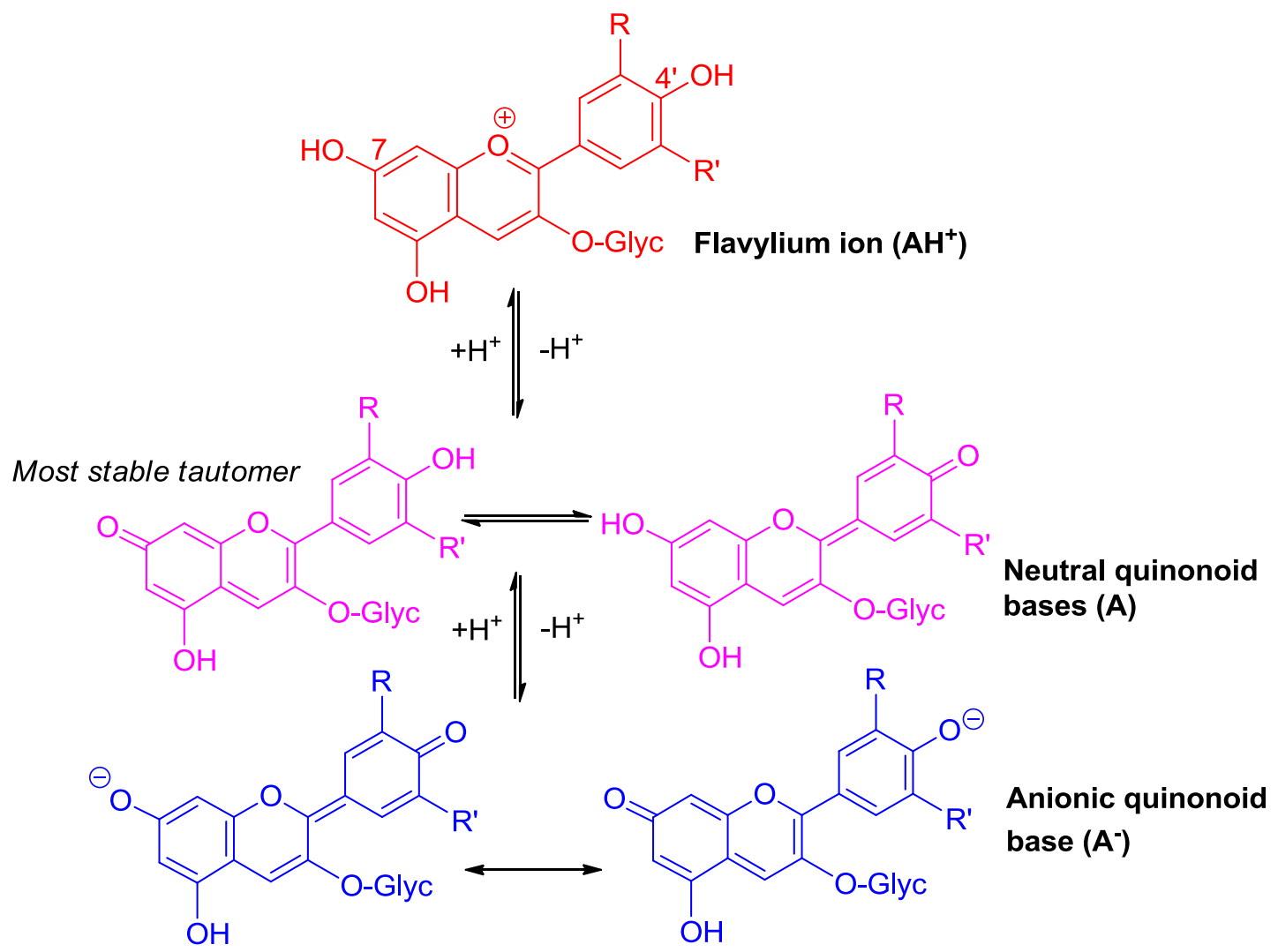

Figure 1. Flavylium ions are weak diacids.
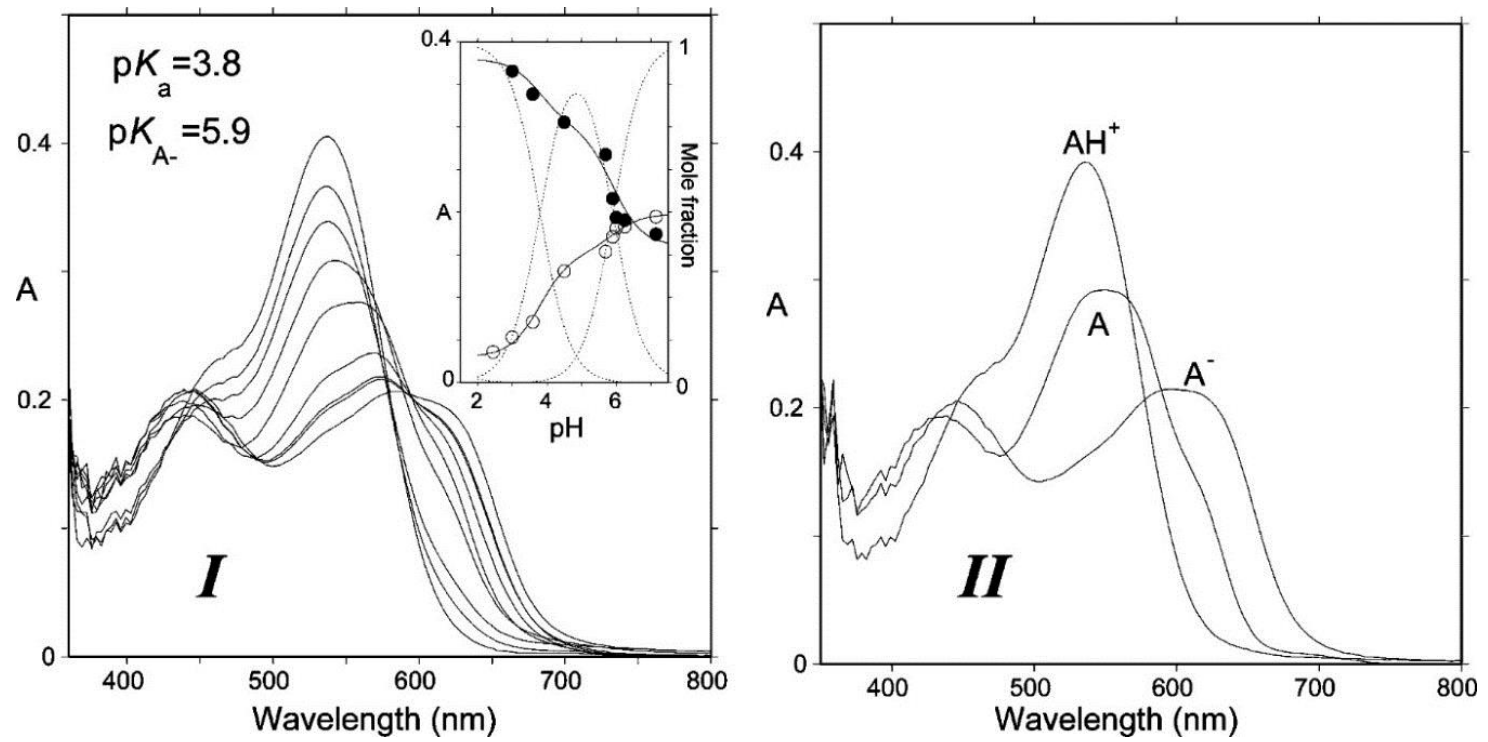

Figure 2. (I) Absorption spectra of Cat-Mv3Glc: $\mathrm{pH}$ jump from $\mathrm{pH}=1.0$ (100\% flavylium) to $\mathrm{pH} 3.00$, $3.59,4.50,5.70,5.96,6.25$, and 7.15, respectively. Spectra recorded $10 \mathrm{~ms}$ after mixing (negligible water addition). (II) Spectra of the components obtained by mathematical decomposition. From [4] with permission of the American Chemical Society. 


\subsection{Anthocyanins Are Hard and Soft Electrophiles}

By analogy with enones, the C2 and C4 atoms of the pyrylium ring can be regarded as hard and soft electrophilic centers, respectively. Hence, they respectively react with hard (O-centered) and soft (S- and C-centered) nucleophiles, the first mechanism being driven by local charges and the second one by interactions between the frontier molecular orbitals (HOMO of nucleophiles and LUMO of electrophiles).

\subsubsection{Nucleophilic Addition at C2}

Water addition is the ubiquitous process taking place within aqueous anthocyanin solutions [1,2]. It leads to the colorless hemiketal (Figure 3) and can be characterized by the thermodynamic hydration constant $K_{\mathrm{h}}$, or as an acceptable approximation (chalcones making only a minor contribution, typically less than $20 \%$, of the total pool of colorless forms), by the apparent constant $K^{\prime}{ }_{\mathrm{h}}$ connecting the flavylium ion and the colorless forms taken collectively. With common anthocyanins, $\mathrm{p} K^{\prime}{ }_{\mathrm{h}}$ lies in the range of $2-3$, which means that hydration is thermodynamically more favorable than proton transfer $\left(\mathrm{pK}_{\mathrm{h}}^{\prime}<\mathrm{p} K_{\mathrm{a} 1}\right)$. Fortunately, it is also much slower, and its $\mathrm{pH}$-dependent kinetics can be quantified by the apparent rate constant of hydration $\left(k_{\mathrm{obs}}\right)$ (Equation $(1), h=\left[\mathrm{H}^{+}\right], \chi_{\mathrm{AH}}=$ mole fraction of $\mathrm{AH}^{+}$within the mixture of colored forms [2,5]:

$$
k_{o b s}=k_{h} \chi_{A H}+k_{-h}^{\prime} h=\frac{k_{h}}{1+K_{a 1} / h+K_{a 1} K_{a 2} / h^{2}}+k_{-h}^{\prime} h
$$

$k_{\mathrm{h}}$ is the absolute rate constant of water addition, $k_{-\mathrm{h}}^{\prime}$ is the apparent rate constant of water elimination (from the mixture of hemiketal and cis-chalcone in fast equilibrium), and $K_{h}^{\prime} \approx k_{\mathrm{h}} / k^{\prime}{ }_{-\mathrm{h}}$ (trans-chalcone neglected). Equation (1) can be easily understood by keeping in mind that the flavylium ion is the sole colored form that is electrophilic enough to directly react with water.

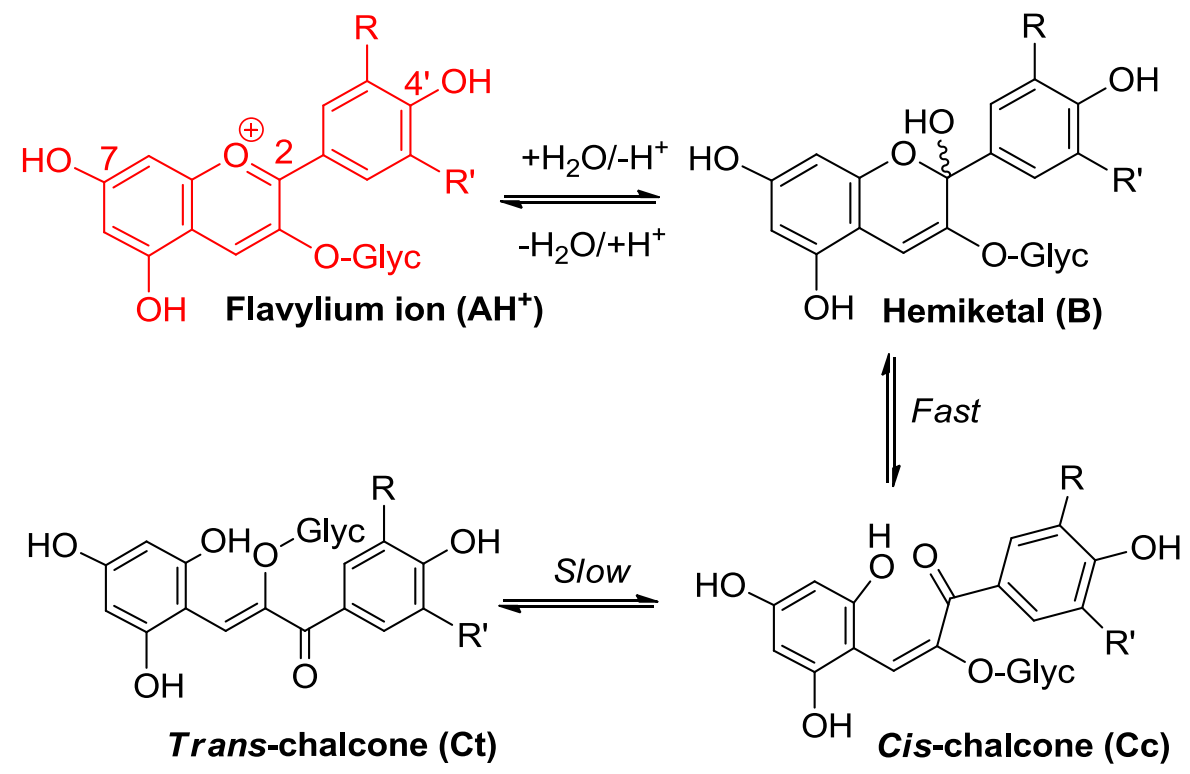

Figure 3. Flavylium ions are hard electrophiles reacting at $\mathrm{C} 2$ with $\mathrm{O}$-centered nucleophiles, such as water (water addition followed by formation of minor concentrations of chalcones).

At a given $\mathrm{pH}$, the initial visible absorbance $\left(A_{0}\right)$ (no colorless forms) and the final visible absorbance $\left(A_{\mathrm{f}}\right)$ (hydration equilibrium established) can be easily related through Equation (2):

$$
\frac{A_{f}}{A_{0}}=\frac{1+K_{a 1} / h+K_{a 1} K_{a 2} / h^{2}}{1+\left(K_{a 1}+K_{h}^{\prime}\right) / h+K_{a 1} K_{a 2} / h^{2}} .
$$


Thus, the magnitude of color loss can be expressed as (Equation (3)):

$$
\frac{A_{0}-A_{f}}{A_{0}}=\frac{K_{h}^{\prime} / h}{1+\left(K_{a 1}+K_{h}^{\prime}\right) / h+K_{a 1} K_{a 2} / h^{2}}
$$

From typical values for the rate and thermodynamic constants of common anthocyanins, simulations of the $\mathrm{pH}$ dependence of the apparent rate constant and percentage of color loss can be constructed (Figure 4). The plots clearly show that the reversible color loss due to water addition to the flavylium ion becomes slower at higher $\mathrm{pH}$ (less flavylium in solution), whereas its magnitude becomes larger because of the higher stability of the colorless forms. The typical time-dependence of the visible spectrum during water addition is shown in Figure 5 [4].

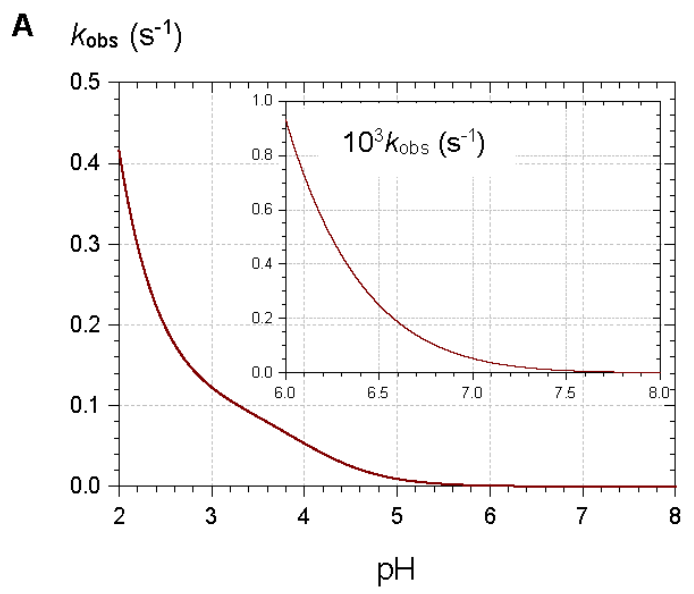

B $\left(A_{0}-A_{\mathrm{f}}\right) / A_{0}$

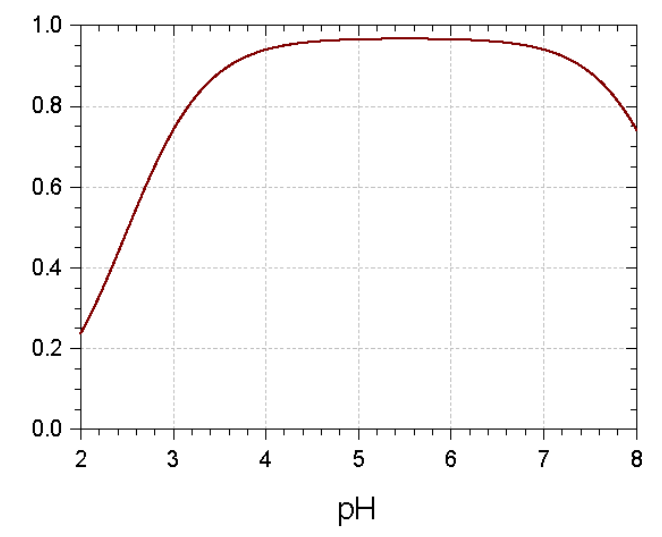

Figure 4. Simulations of the $\mathrm{pH}$ dependence of the apparent rate constant $(\mathbf{A})$ and relative magnitude (B) of color loss. Selected values for parameters: $\mathrm{p} K_{\mathrm{a} 1}=4, \mathrm{p} K_{\mathrm{a} 1}=7, \mathrm{p} K_{\mathrm{h}}^{\prime}=2.5, k_{\mathrm{h}}=0.1 \mathrm{~s}^{-1}$, $k_{-}^{\prime} \approx k_{\mathrm{h}} / K_{\mathrm{h}}^{\prime}$.
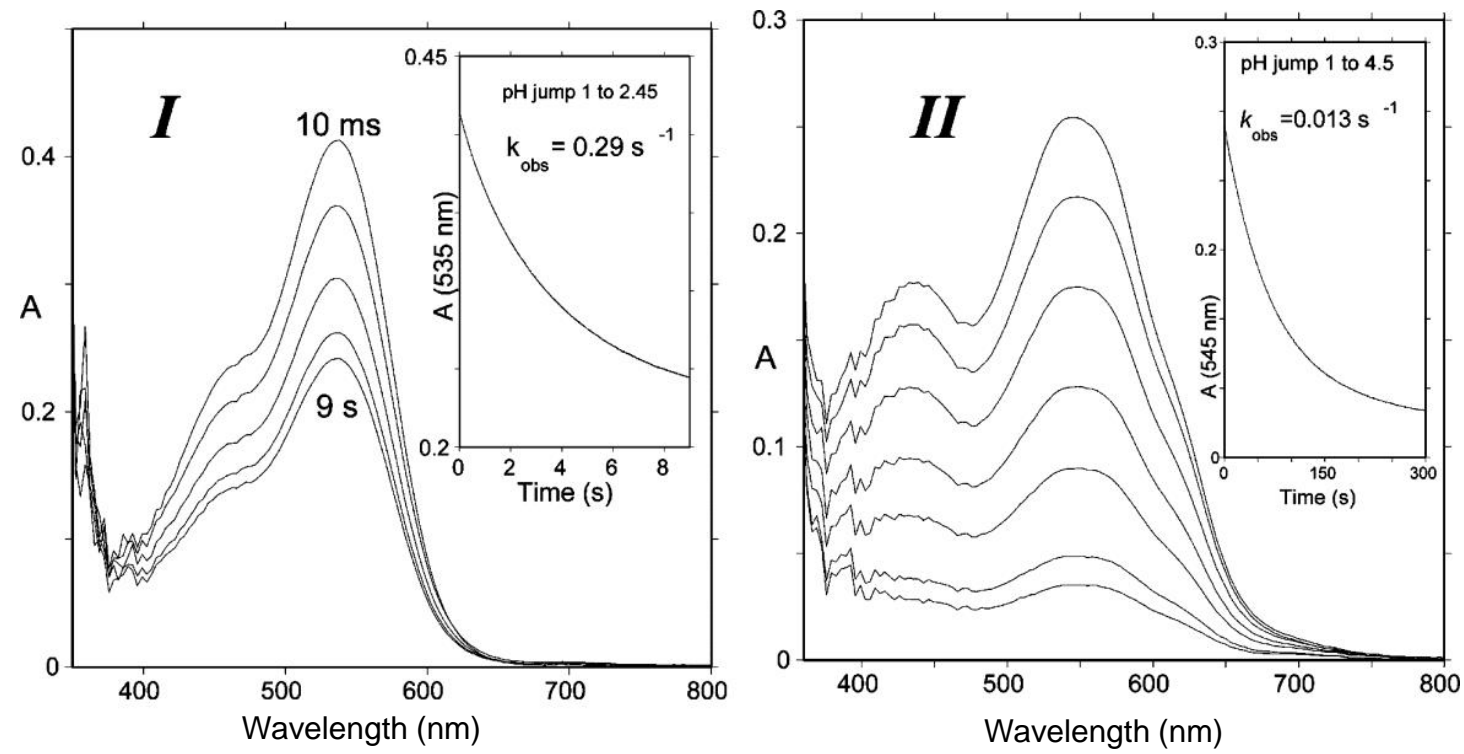

Figure 5. (I) Spectral changes of Cat-Mv3Glc between $10 \mathrm{~ms}$ and $9 \mathrm{~s}$ following a $\mathrm{pH}$ jump from $\mathrm{pH}=1$ to $\mathrm{pH}=2.45$; half-life of flavylium $=2.4 \mathrm{~s}$. (II) $\mathrm{pH}$ jump from $\mathrm{pH}=1$ to $\mathrm{pH}=4.5$; half-life of quinonoid bases $=53.3 \mathrm{~s}$. At $\mathrm{pH}=6$, the half-life of quinonoid bases $\approx 30 \mathrm{~min}$. From reference [4] with permission of the American Chemical Society. 
Near neutrality water addition is so slow (fraction of flavylium ion $<0.1 \%$ ) that the colored forms (mixtures of neutral and anionic bases) can, in principle, persist for hours. However, such a reasoning ignores the irreversible mechanisms of color loss taking place near neutrality as the anionic base is obviously much more sensitive to autoxidation (non-enzymatic oxidation by $\mathrm{O}_{2}$ triggered by transition metal traces) than the flavylium ion. These mechanisms will be addressed in Section 2.4.1.

\subsubsection{Nucleophilic Addition at C4}

Bisulfite is an antimicrobial and anti-browning agent that is frequently used in the food industry. As a S-centered nucleophile, it reversibly reacts with the flavylium ion at C4, thus yielding colorless adducts (Figure 6) [6]. No such adducts have been identified so far by simply reacting anthocyanins with natural thiols such as cysteine and glutathione (GSH). Unlike bisulfite, which is actually the conjugated base of $\mathrm{SO}_{2}\left(\mathrm{pK}_{\mathrm{a}} \approx 1.8\right)$ and can coexist with the flavylium ion under acidic conditions, thiolate anions $\left(\mathrm{p} K_{\mathrm{a}}=8-9\right)$ are usually formed at much higher $\mathrm{pH}$ levels where the flavylium ion is only present as traces.

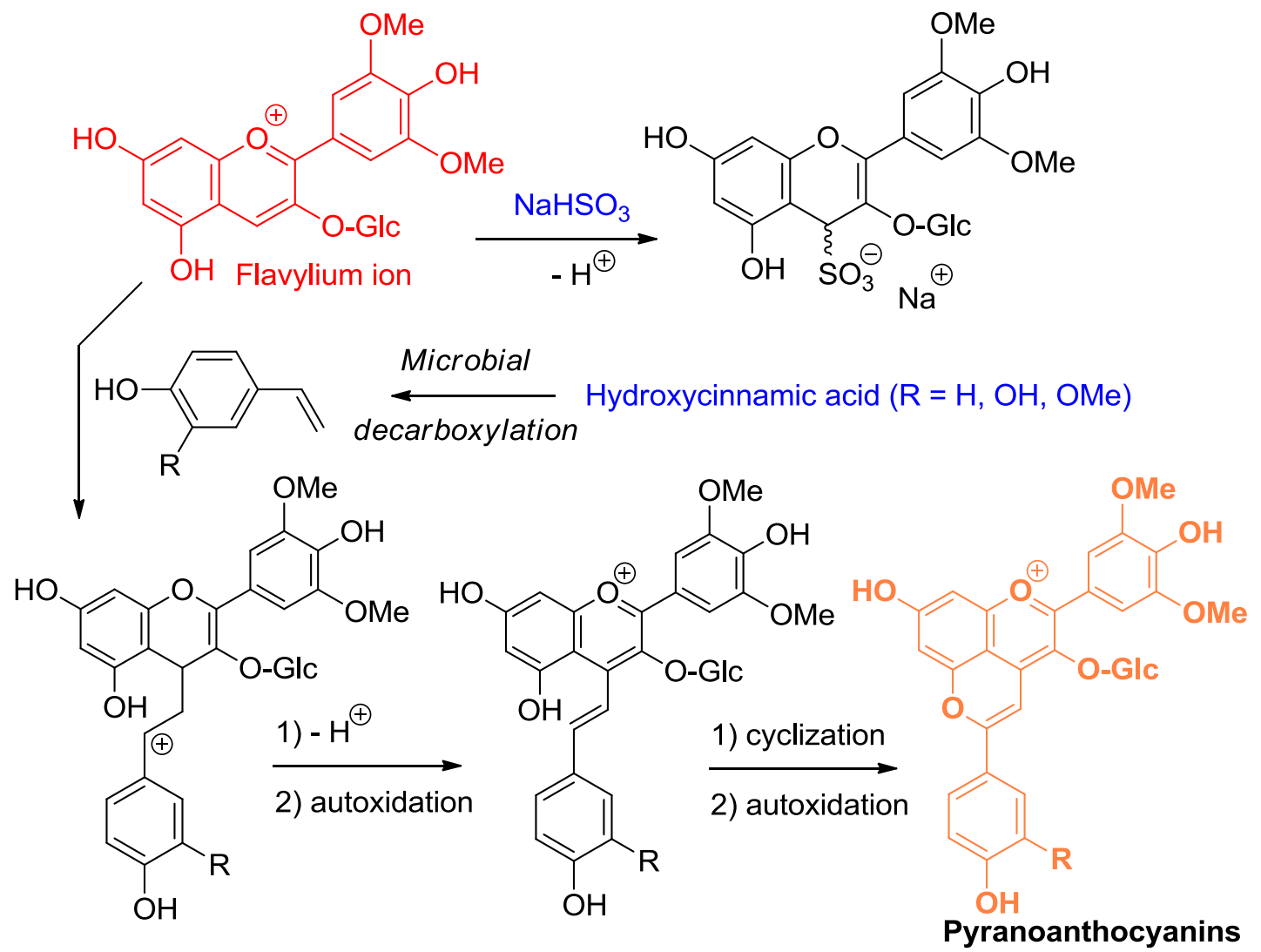

Figure 6. Flavylium ions are soft electrophiles that react at C4 with S- and C-centered nucleophiles, such as bisulfite and 4-vinylphenols.

A variety of C-centered nucleophiles are also known to add to the flavylium ion, and this chemistry underlies the color changes observed in red wine upon aging [7]. In this context, the most important C-centered nucleophiles are electron-rich $\mathrm{C}-\mathrm{C}$ double bonds, such as 4-vinylphenols (4-hydroxystyrenes), formed upon microbial decarboxylation of 4-hydroxycinnamic acids (Figure 6) and the enol forms of various aldehydes and ketones such as pyruvic acid and ethanal (acetaldehyde) [8,9]. In the process, new pigments, called pyranoanthocyanins, are formed, which are resistant to nucleophilic addition at C2 and C4 [10-12]. Their color (shifted to orange-red, compared to the corresponding flavylium ion) is thus more stable. Through their nucleophilic C6- and C8-atoms, 
flavanols and proanthocyanidins can also add to the electrophilic C4 center of anthocyanins [13]. However, the flavene intermediate thus formed is not accumulated and evolves through two possible routes: (a) under strongly acidic conditions $(\mathrm{pH}=2)$, protonation at $\mathrm{C} 3$ allows a second nucleophilic attack by a nearby phenolic $\mathrm{OH}$ group of the tannin to yield a colorless product (see Section 2.3 for a similar mechanism); or (b) under moderately acidic conditions $(\mathrm{pH}=3-6)$, dehydration with concomitant formation of an additional pyrane ring is favored and a new pigment bearing a xanthylium chromophore is formed.

With its enediol structure, ascorbate (vitamin C) can also react with flavylium ions at C4 but the corresponding adducts have not been reported so far.

\subsection{Anthocyanin Hemiketals Are Nucleophiles}

Basic organic chemistry teaches that electron-donating substituents of benzene rings accelerate aromatic electrophilic substitutions $\left(S_{\mathrm{E}} A r\right)$ and orient the entering electrophiles to the ortho and para positions. In that perspective, the phloroglucinol (1,3,5-trihydroxybenzene) ring (A-ring) of anthocyanins must be especially favorable to $S_{\mathrm{E}} A r$ as the three $\mathrm{O}$-atoms combine their electronic effects to increase the reactivity of $\mathrm{C} 6$ and $\mathrm{C} 8$. However, the pyrylium ring (C-ring) of the flavylium ion (and, to a lesser degree, the enone moiety of chalcones) is strongly electron-withdrawing, so that only the hemiketal is expected to react by $S_{\mathrm{E}} A r$.

Here, again, wine chemistry provides interesting examples of $S_{\mathrm{E}} A r$ between anthocyanins and various carbocations derived from other wine components (Figure 7) [7]. For instance, wine pigments in which anthocyanins and flavanols are linked though an ethylidene bridge between their C6- and/or C8-atoms are formed by double $S_{\mathrm{E}} A r$ between A-rings and ethanol [14,15]. The likely intermediates in the reaction are the 6- or 8-vinyl-flavanol and the 6- or 8-vinyl-anthocyanin hemiketals, the protonation of which delivers a benzylic cation that is directly involved in the $S_{\mathrm{E}} A r$ reaction. Of course, in addition to the cross reaction products, anthocyanin-ethylidene-anthocyanin and flavanol-ethylidene-flavanol adducts can also form oligomers and mixed oligomers [16]. Even, pyranoanthocyanins stemming from the nucleophilic attack of vinyl-phenols at $\mathrm{C} 4$ of anthocyanins can be produced.

Flavanol carbocations formed by acidic cleavage of the inter-flavan linkage of proanthocyanidins also react with anthocyanin hemiketals by $S_{\mathrm{E}} A r$ [17]. Interestingly, both direct and ethylidene-bridged flavanol-anthocyanin adducts are more purple than the native anthocyanin, but only the latter expresses a color that is stable, i.e., a flavylium nucleus that is less sensitive to water addition $[4,18]$. A possible explanation is that ethylidene-bridged flavanol-anthocyanin adducts are prone to non-covalent self-association by $\pi$-stacking, which provides a less aqueous environment for the flavylium nuclei.

Water elimination from the anomeric C-atom of the ellagitannin vescalagin (abundant in oak barrels) also delivers a carbocation for direct coupling with wine anthocyanins [19] and subsequent modest protection against water addition [20]. Finally, the anthocyanin hemiketal can react with the flavylium ion itself, and this pathway provides a route for anthocyanin oligomerization, a poorly documented mechanism as the corresponding oligomers are probably difficult to evidence and quantify. However, an oenin trimer has been found in Port wine, and its structure has been fully elucidated by NMR [21]. The two linkages are of the C4-C8 type. As in the direct flavanol-anthocyanin coupling (see Section 2.2.2), flavene intermediates evolve by $\mathrm{C}-\mathrm{O}$ coupling and only the lower unit remains colored. Similar oligomers also occur with 3-deoxyanthocyanidins, e.g., in red sorghum, but the detailed structures remain unknown [22].

Anthocyanin hemiketals can also react by Michael addition with o-quinones formed by two-electron oxidation of catechols, such as epicatechin [13] and caffeoyltartaric acid [23]. 


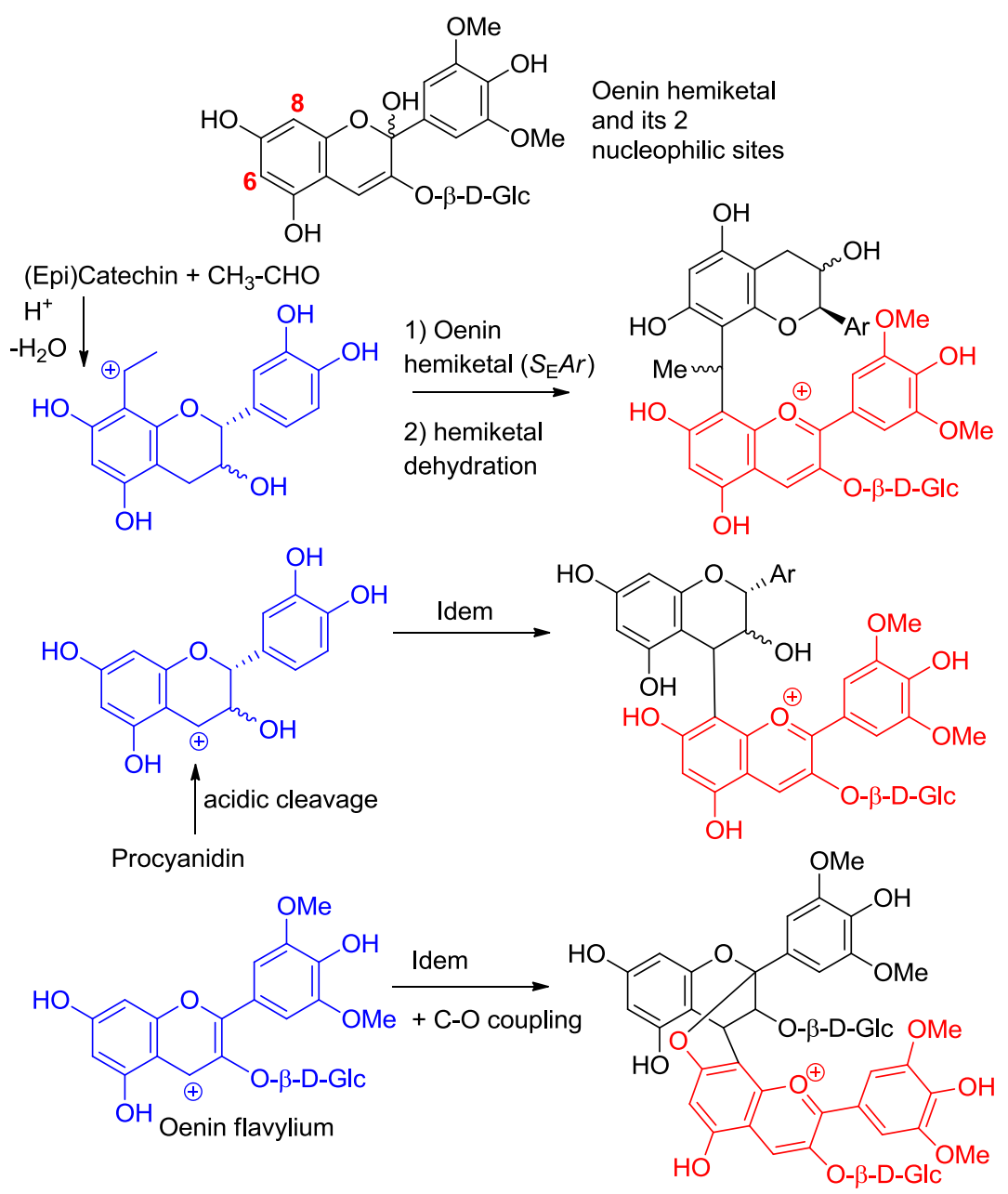

Figure 7. Anthocyanin hemiketals are nucleophiles reacting with carbocations $(\mathrm{Ar}=$ catechol ring).

\subsection{Anthocyanins Are Electron-Donors}

Many polyphenols, especially those containing electron-rich catechol (1,2-dihydroxybenzene) or pyrogallol (1,2,3-trihydroxybenzene) nuclei are good electron- or H-donors. Electron transfer is typically faster when the $\mathrm{pH}$ is raised, i.e., when the fraction of phenolate anion (a much better electron-donor than the parent phenol) increases. Electron transfer from phenols is involved in their oxidation mechanisms and also underlies the most common mechanism of antioxidant activity, i.e., the reduction of reactive oxygen species (ROS) involved in oxidative stress from plants to humans. Anthocyanins are known to be thermally unstable, especially under neutral conditions, and various degradation products have been identified. Their antioxidant activity has been also established in various chemical models. However, detailed knowledge on the mechanisms involved and on the relative contributions of the different colored and colorless forms is still missing.

\subsubsection{Oxidation}

Anthocyanins are among the least thermally stable flavonoids. Anthocyanidins, the corresponding aglycones, are actually only stable under highly acidic conditions and are extensively degraded in less than one hour under physiological conditions $\left(\mathrm{pH}=7.4,37^{\circ} \mathrm{C}\right)[24,25]$. From the structure of the degradation products, it is clear that a combination of hydrolytic and autoxidative pathways operate, leading to cleavage of the $\mathrm{C} 2-\mathrm{C} 1^{\prime}, \mathrm{C} 2-\mathrm{C} 3$ and C3-C4 bonds (Figure 8) $[13,26,27]$. A mechanism involving pre-formed hydrogen peroxide actually accounts for the formation of some cleavage products (Figure 9). The critical step is the addition of $\mathrm{H}_{2} \mathrm{O}_{2}$ (a hard nucleophile) at $\mathrm{C} 2$ of the flavylium ion, 
followed by Baeyer-Villiger rearrangement, which opens routes for cleavage of the $\mathrm{C} 2-\mathrm{C} 1^{\prime}$ and $\mathrm{C} 2-\mathrm{C} 3$ bonds $[13,26]$. However, the preliminary formation of $\mathrm{H}_{2} \mathrm{O}_{2}$ remains unclear and must involve the direct autoxidation of anthocyanins. Thus, an alternative mechanism beginning by electron or $\mathrm{H}$-atom transfer (mediated by unidentified transition metal traces) from the anionic or neutral base to $\mathrm{O}_{2}$ would deliver a highly delocalized radical that is susceptible to $\mathrm{O}_{2}$ addition at different centers (Figure 10). The cleavage of hydroperoxide intermediates thus formed could also yield the degradation products detected.<smiles>[R]c1cc(C(=O)O)cc([R])c1O</smiles>

Figure 8. Pathways of anthocyanin degradation.

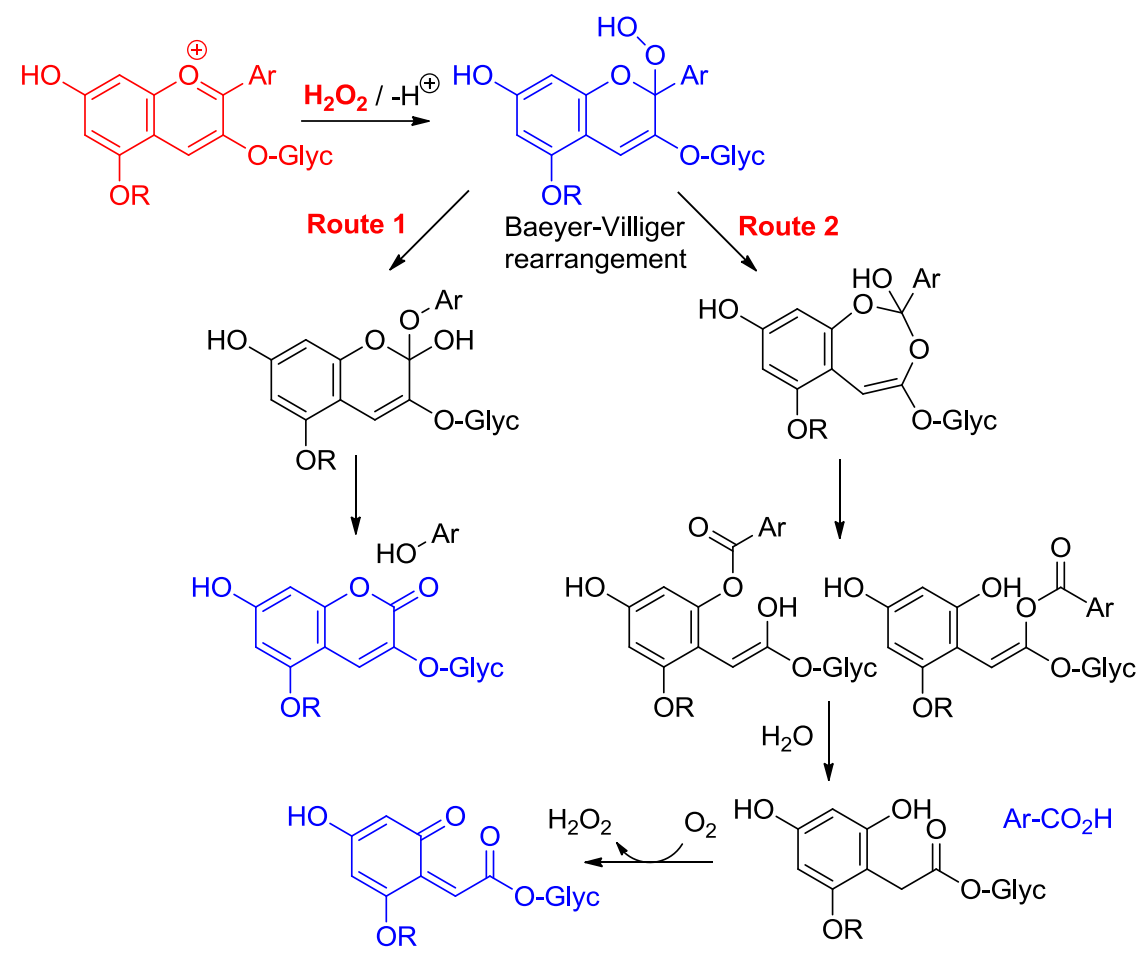

Figure 9. Possible mechanisms of anthocyanin degradation with pre-formed hydrogen peroxide. 


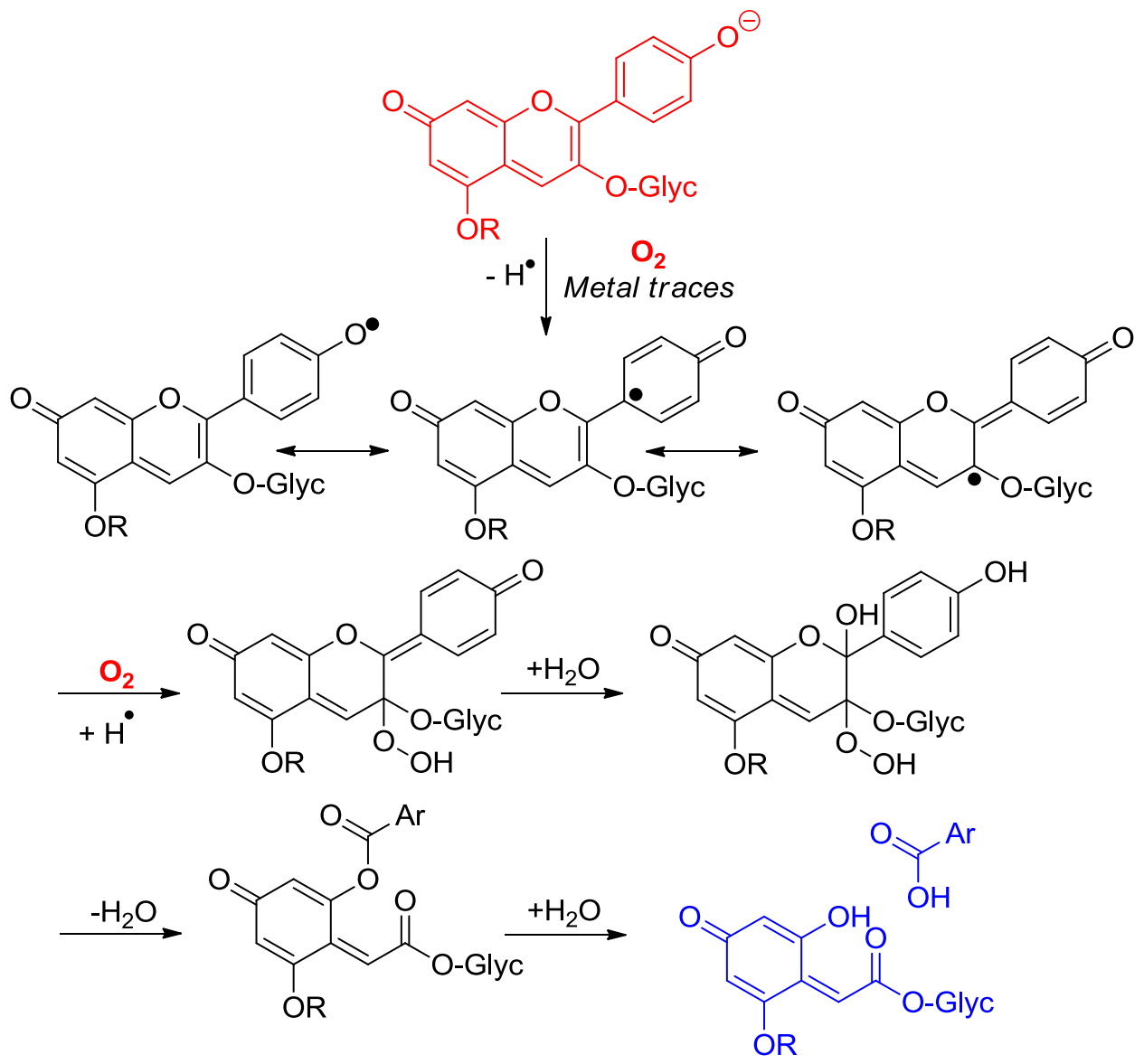

Figure 10. Possible mechanisms of anthocyanin degradation without pre-formed hydrogen peroxide.

\subsubsection{Antioxidant Activity}

Anthocyanins under their native forms can transfer electrons to ROS and could, therefore, provide protection to important oxidizable biomolecules, such as polyunsaturated fatty acids (PUFAs), proteins, and DNA. The relevance of such phenomena is probably much higher in food preservation than in nutrition and health, given the current knowledge on anthocyanin bioavailability (see Section 3). In this section, we simply mention that anthocyanins can indeed effectively reduce one-electron oxidants such as the stable radical DPPH (2,2-diphenyl-1-picrylhydrazyl). Structure-activity relationships show that hydroxylation at $\mathrm{C}^{\prime}$ and $\mathrm{C}^{\prime}$ increases the $\mathrm{H}$-donating capacity, thus suggesting that the B-ring is primarily involved in electron donation [28]. Comparing oenin and the flavanol catechin shows that the transfer of the first (most labile) H-atom to DPPH is roughly as fast for both flavonoids but that oenin reduces at least twice as many radicals than catechin (Table 1) [29]. This advantage must be rooted in the extensive oxidative degradation undergone by oenin during the $\mathrm{DPPH}$-scavenging process with the transient formation of intermediates (possibly, syringic acid) retaining a substantial electron-donating activity. It is also remarkable that the wine pigments combining the oenin and catechin units retain a high but contrasting DPPH-scavenging activity [29]: the direct coupling between the two flavonoid units results in a faster first $\mathrm{H}$-atom transfer (higher $k_{1}$ ) but markedly lowers the total number of radicals reduced $\left(n_{\text {tot }}\right)$, whereas the coupling through an ethylidene bridge apparently leaves each unit free to independently react with DPPH $\left(k_{1}\right.$ almost unchanged, approximate additivity in the $n_{\text {tot }}$ value), as observed with the equimolar oenin-catechin mixture (Table 1). 
Table 1. Antioxidant activity of malvidin 3-O- $\beta$-D-glucoside (oenin) and related pigments: reduction of the DPPH (2,2-diphenyl-1-picrylhydrazyl) radical $\left(\mathrm{MeOH}, 25^{\circ} \mathrm{C},{ }^{1}\right.$ and $\left.{ }^{2}\right)$ and inhibition of hemeinduced peroxidation of linoleic acid ( $0.1 \mathrm{mM}$ linoleic acid in acetate buffer $+2 \mathrm{mM}$ Tween-20, $0.1 \mu \mathrm{M}$ metmyoglobin, $\mathrm{pH}=4,37^{\circ} \mathrm{C},{ }^{3}$ ). From reference [29].

\begin{tabular}{cccc}
\hline Antioxidant & $\boldsymbol{n}_{\text {tot }} \mathbf{1}$ & $\boldsymbol{k}_{\mathbf{1}} / \mathbf{s}^{-\mathbf{1 2}}$ & $\mathbf{I C}_{\mathbf{5 0}} / \boldsymbol{\mu} \mathbf{M}^{\mathbf{3}}$ \\
\hline Oenin & $11.26( \pm 0.08)$ & $910( \pm 70)$ & 0.68 \\
Catechin & $4.86( \pm 0.03)$ & $1200( \pm 110)$ & 0.27 \\
Oenin + Catechin $(1: 1)$ & $14.04( \pm 0.10)$ & $1160( \pm 330)$ & nd \\
$(R)$-Catechin-8-CHMe-8-Oenin & $14.56( \pm 0.03)$ & $1000( \pm 320)$ & 0.15 \\
(S)-Catechin-8-CHMe-8-Oenin & $14.61( \pm 0.18)$ & $600( \pm 120)$ & 0.41 \\
Catechin-4,8-Oenin & $7.16( \pm 0.08)$ & $5120( \pm 1050)$ & 0.60 \\
\hline
\end{tabular}

${ }^{1}$ Antioxidant stoichiometry (number of DPPH radicals reduced per antioxidant molecule). ${ }^{2}$ Rate constant for the transfer of the first $\mathrm{H}$-atom from antioxidant to DPPH. ${ }^{3}$ Antioxidant concentration for a doubling of the period of time required for the accumulation of a fixed concentration of polyunsaturated fatty acid (PUFA) hydroperoxides (conjugated dienes).

Oenin, catechin, and wine pigments were also compared for their ability to inhibit the peroxidation of linoleic acid induced by dietary heme iron in acidic micelle solutions, a chemical model of postprandial oxidative stress in the stomach [29]. As hydrophilic antioxidants, polyphenols are known to act at the initiation stage by reducing the hypervalent iron species $\left(\mathrm{Fe}^{\mathrm{IV}}\right)$ involved in the generation of propagating lipid peroxyl radicals (Figure 11) [30] which, on the other hand, are directly reduced by the typical chain-breaking amphiphilic antioxidant $\alpha$-tocopherol (vitamin E). The highly hydrophilic oenin was found to be less potent than catechin in the inhibition, but coupling both flavonoids via an ethylidene bridge improves their efficiency (Table 1).

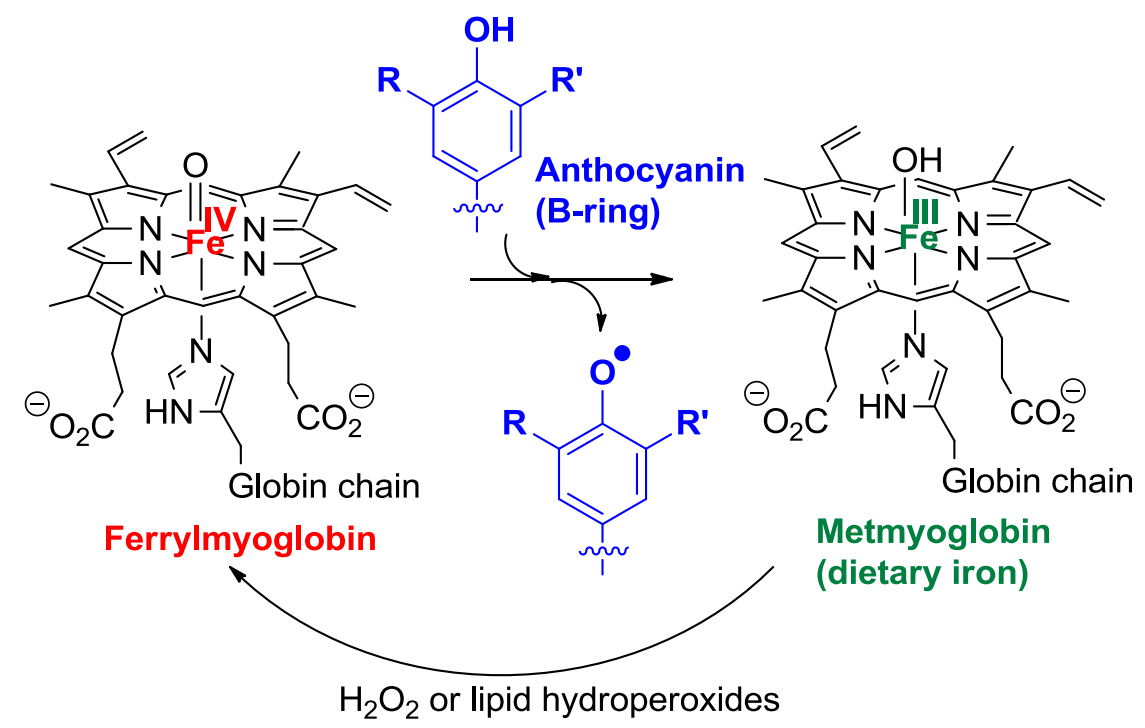

Figure 11. Possible mechanisms for the antioxidant activity of anthocyanins in food and in the gastro-intestinal tract.

Acylation by electron-rich hydroxycinnamic acids, such as sinapic and ferulic acids, potentiates the capacity of anthocyanins to inhibit the diazo-initiated autoxidation of styrene in acetonitrile. In particular, a higher rate constant and stoichiometric factor of radical scavenging were obtained for acylated (vs. non-acylated) anthocyanins [31]. Curiously, this trend could not be confirmed for the peroxidation of linoleic acid in micelles, as if the intrinsic differences in electron-donating activity were counterbalanced by differences in the partition of anthocyanins between micelles and the aqueous phase. 


\subsection{Anthocyanin Complexes}

Phenolic nuclei have an intrinsic ability to develop molecular (non-covalent) interactions as they combine flat polarizable apolar surfaces (the aromatic nuclei) for strong dispersion interactions and polar $\mathrm{OH}$ groups that are susceptible to acting as $\mathrm{H}$-bond donors and acceptors.

\subsubsection{Self-Association and Co-Pigmentation}

One of the most remarkable properties of the anthocyanin chromophores is their ability to develop $\pi$-stacking interactions [32-34], mostly driven by dispersion interactions and the concomitant favorable release of water molecules from the solvation shells of the interacting nuclei, known as the hydrophobic effect. Owing to their planar structures and extended electron delocalization over the three rings, the colored forms are much more prone to $\pi$-stacking interactions than the colorless forms, for which such interactions, although not necessarily absent, are typically neglected. Examples of $\pi$-stacking interactions with anthocyanins are self-association and binding between anthocyanins and other phenols, a phenomenon called co-pigmentation. The affinity of co-pigments for a given anthocyanin (as measured by the corresponding thermodynamic binding constant) decays along the series: planar flavonoids (flavones, flavonols) $>$ non-planar flavonoids (catechins), hydroxycinnamic acids $>$ hydroxybenzoic acids [32]. As for self-association, it is stronger for the neutral base than for the flavylium ion and the anionic base, as the latter stacks are destabilized by charge repulsion.

The spectral consequences of co-pigmentation are summarized in Figure 12 with malvin (malvidin 3,5 -di-O- $\beta$-glucoside) and a highly water-soluble rutin (quercetin $3-O-\beta$-rutinoside) derivative [35]. In strongly acidic solutions (negligible water-to-flavylium addition), $\pi$-stacking interactions between the two partners promote bathochromism as a consequence of co-pigment-to-pigment charge transfer. Changes in color intensity simply reflect differences between the molar absorption coefficients of free and bound pigments. Under the mildly acidic conditions typically encountered in natural media, pigment-co-pigment interactions also promote hyperchromism, which can be understood as a shift in the now established flavylium-hemiketal equilibrium toward the colored form, which is selectively stabilized by its association with the co-pigment. This combination of bathochromic and hyperchromic shifts makes co-pigmentation one of the most important mechanisms for color variation and stabilization in plants. It can also be noted that heating usually attenuates the hyperchromic shift (Figure 12) as a consequence of the exothermic character of co-pigmentation $\left(\Delta H^{0}<0\right)$.
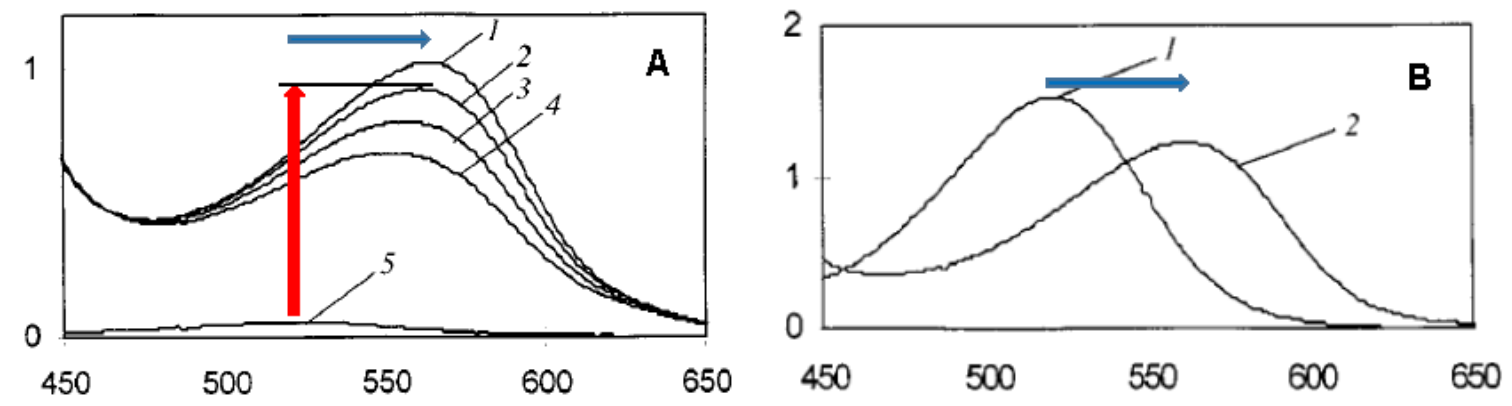

$\mathrm{Nnm}$

Figure 12. Co-pigmentation of malvin (malvidin 3,5-diglucoside, $50 \mu \mathrm{M}$ ) by rutin bis(hydrogensuccinate) (mixture of 3 regioisomers, 200 equiv.). (A) $\mathrm{pH}=3.5$, malvin + co-pigment at $\mathrm{T}=15.5$ (1), 25.0 (2), 35.0 (3), 44.2 (4) ${ }^{\circ} \mathrm{C}$, malvin alone at $\mathrm{T}=25.3{ }^{\circ} \mathrm{C}$ (5). (B) $\mathrm{pH}=0.9, \mathrm{~T}=25.0{ }^{\circ} \mathrm{C}$, malvin alone (1), malvin + co-pigment (2). Adapted from reference [35].

The possibility of developing $\pi$-stacking interactions increases with the acylation of anthocyanins on their glycosyl moieties by hydroxycinnamic acid (HCA) residues. Indeed, depending on the location and number of HCA residues, different spatial arrangements can be observed (Figure 13) [34]: 
- Intramolecular co-pigmentation: $\pi$-stacking interactions promote a conformational folding of the pigment bringing one or more HCA residue(s) into contact with the chromophore;

- Enhanced self-association: the HCA residues can stabilize the chiral stacking of chromophores evidenced by circular dichroism.
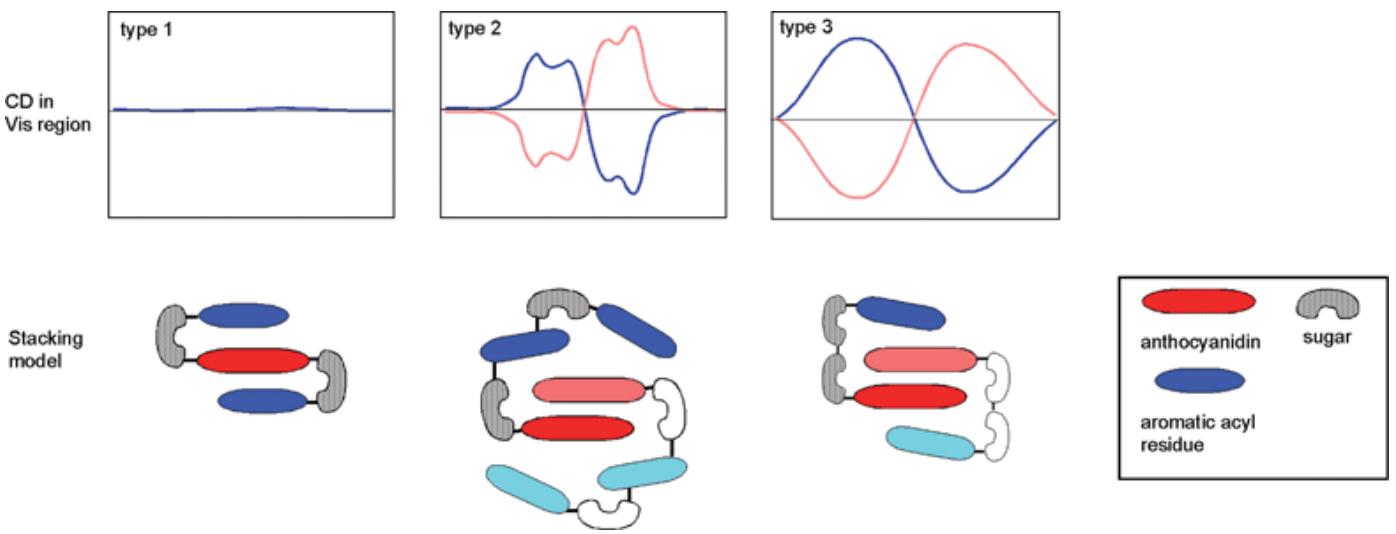

Figure 13. Acylated anthocyanins: discrimination of intramolecular co-pigmentation (type 1) and self-association (types 2 and 3) by circular dichroism (pink or blue CD spectra depending on the chirality of the stacks). From [34] with permission of the Royal Society of Chemistry.

In such assemblies, the flavylium nucleus has restricted access to the water solvent. Consequently, the thermodynamics of water addition are less favorable (increased $\mathrm{pK}_{\mathrm{h}}^{\prime}$ ), and the percentage of colored forms at equilibrium increases [5,36-38]. For instance, at $\mathrm{pH}=3$, ca. $90 \%$ of the triacylated Morning glory pigment is still in colored form (mostly flavylium) vs. $15 \%$ for its non-acylated counterpart (Figure 14). Its vulnerability to water addition prevents the non-acylated pigment from accumulating the neutral quinonoid base at higher $\mathrm{pH}$ levels, and the corresponding solutions are almost colorless. In contrast, $30 \%$ of the triacylated pigment is present as the colored neutral base at $\mathrm{pH}=5$. Moreover, the $\pi$-stacking interactions developed by the triacylated flavylium ion induce a $20 \mathrm{~nm}$ bathochromic shift of its $\lambda_{\max }$ compared to its non-acylated counterpart.

Anthocyanins with an o-dihydroxy substitution on their B-ring (cyanidin, delphinidin, and petunidin derivatives) also bind hard metal ions, such as $\mathrm{Al}^{3+}$ and $\mathrm{Fe}^{3+}$, in mildly acidic to neutral solution. As the anthocyanin binds as the quinonoid base with additional proton loss from $\mathrm{C}^{\prime}-\mathrm{OH}$, bathochromism is observed with additional ligand-to-metal charge transfer with $\mathrm{Fe}^{3+}$ (Figure 15).

Mole fraction
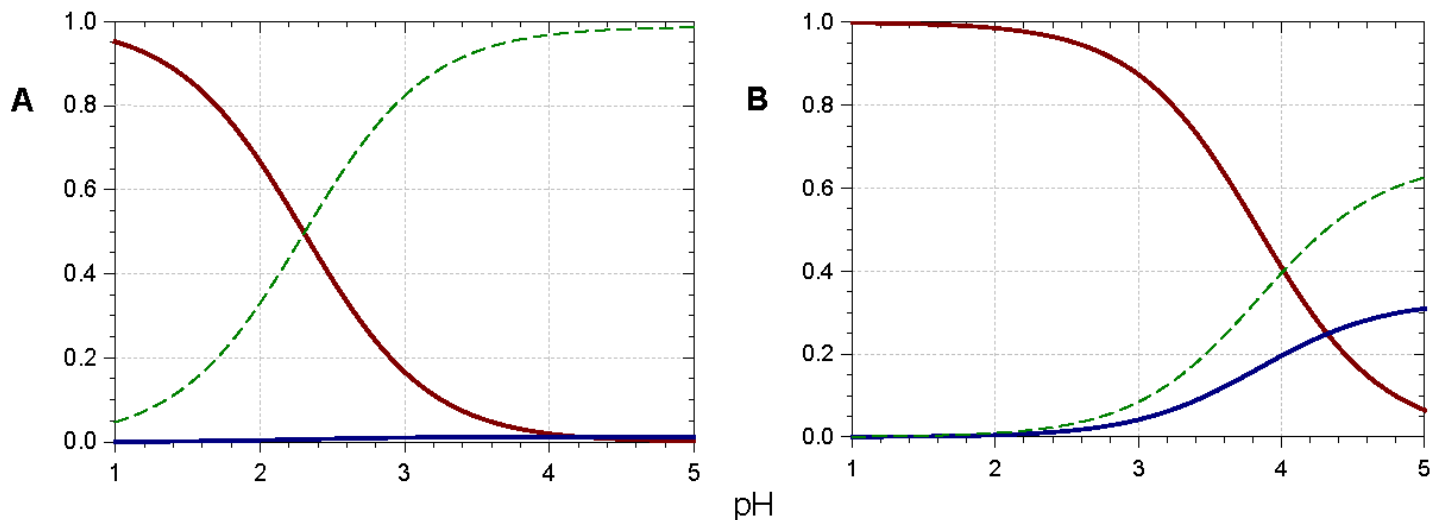

Figure 14. Cont. 


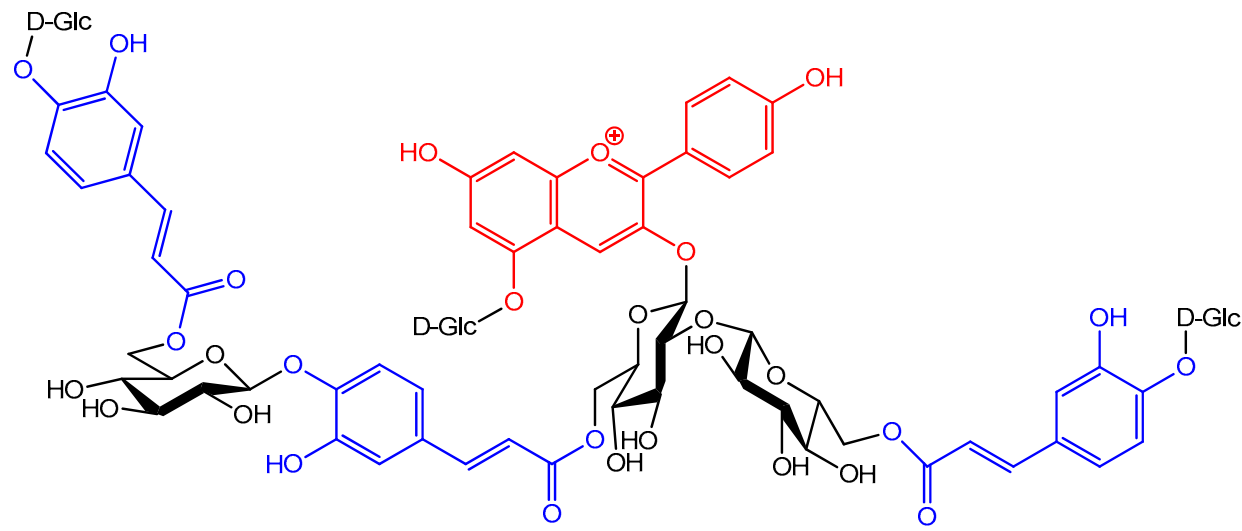

Figure 14. Triacylated (B) vs. non-acylated (A) Morning glory (Pharbitis nil) anthocyanins: equilibrium distribution of anthocyanin species in aqueous solution. Red solid line: flavylium ion, blue solid line: neutral base, dotted green line: total colorless forms. Parameters for plots are $\mathrm{p} K^{\prime}{ }_{\mathrm{h}}=2.30$, $\mathrm{p} K_{\mathrm{a} 1}=4.21(\mathbf{A}) ; \mathrm{p} K_{\mathrm{h}}^{\prime}=4.01, \mathrm{p} K_{\mathrm{a} 1}=4.32(\mathbf{B})$. From [36,37].

A

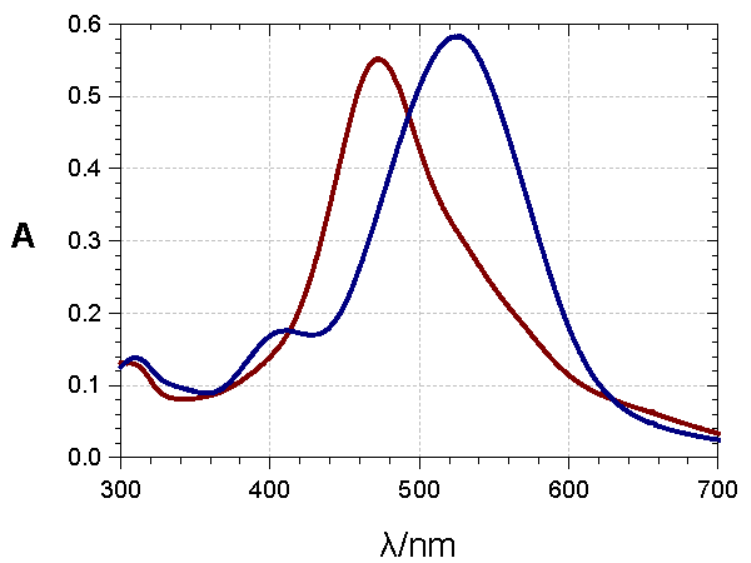

Mole fraction

B

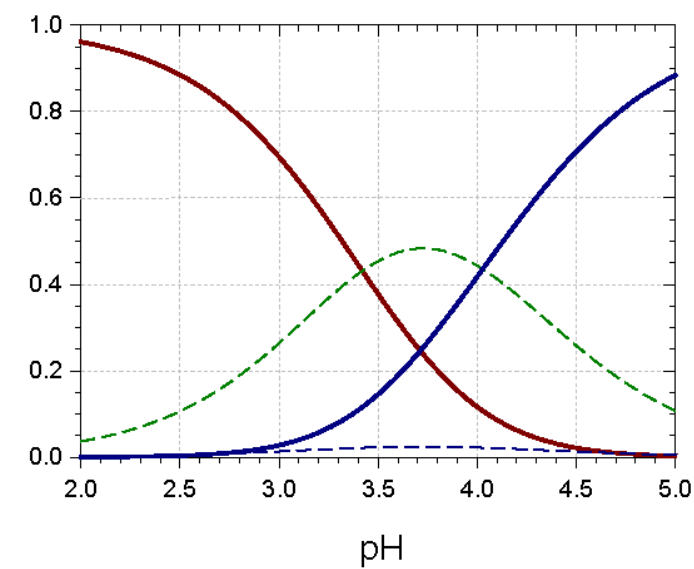

Figure 15. (A) $3^{\prime}, 4^{\prime}$-Dihydroxy-7-O- $\beta$-D-glucopyranosyloxyflavylium $(50 \mu \mathrm{M})$ in a pH 4 buffer $(0.1 \mathrm{M}$ acetate), red spectrum: before hydration, blue spectrum: 10 min after addition of $\mathrm{Al}^{3+}$ (4 equiv.); (B) equilibrium distribution of species in aqueous solution. Red solid line: flavylium ion, blue dotted line: neutral base, dotted green line: total colorless forms, blue solid line: $\mathrm{Al}^{3+}$ complex. Parameters for plots are $\mathrm{pK}_{\mathrm{h}}^{\prime}=3.42, \mathrm{p} K_{\mathrm{a} 1}=4.72, K_{\mathrm{M}}=2 \times 10^{-4}$. From [39].

At least in mildly acidic solution, metal binding is restricted to the colored forms and thus efficiently competes with the hydration equilibrium, thereby preventing the formation of the colorless forms. In the most sophisticated assemblies, metal binding and $\pi$-stacking interactions combine, thus providing the most common mechanism towards the formation of stable blue colors $[34,40,41]$. In the so-called metalloanthocyanins, a fixed metal-pigment-co-pigment stoichiometry of 2:6:6 is observed: three anthocyanins bind to each metal ion and two equivalent complexes assemble by left-handed $\pi$-stacking interactions between the chromophores. Then, three pairs of flavone or flavonol co-pigments in left-handed $\pi$-stacking intercalate between the pairs of stacked anthocyanins. In this intercalation, right-handed pigment-copigment $\pi$-stacking occurs. Large-scale aggregation of acylated anthocyanins can also result in the formation of highly colored assemblies within the vacuole (the so-called anthocyanin vacuolar inclusions) [42], the organelle where anthocyanins are stored in plant cells. 


\subsubsection{Binding to Biopolymers}

Despite the potential significance of such associations in food chemistry and nutrition, the ability of anthocyanins to bind proteins and polysaccharides is still poorly documented at the molecular level. This paragraph focuses on anthocyanins (glycosides), although anthocyanidins are also commonly investigated. Indeed, aglycones are chemically unstable in mildly acidic and neutral conditions and may be substantially degraded over the duration of analysis.

Saturation transfer difference (STD)-NMR was used to probe the binding of cyanidin and delphinidin 3-glucosides to pectin from citrus fruits $(\mathrm{MM}=111 \mathrm{kDa})$ [43]. Indeed, magnetization transfer (requiring proton pairs distant by less than $0.5 \mathrm{~nm}$ ) from irradiated pectin protons to anthocyanin protons provided direct evidence that the two partners are in close contact. STD titrations at $\mathrm{pH}=4.0$ and $\mathrm{pH}=1.5$ suggest that the flavylium ion has a higher affinity for pectin than the hemiketal. Assuming the Scatchard model ( $n$ identical binding sites having the same binding constant, $K_{\mathrm{b}}$ ), pectin was found to bind 180-600 anthocyanin units depending on the selected anthocyanin and $\mathrm{pH}$. The corresponding $K_{\mathrm{b}}$ values are very weak $\left(<10^{3} \mathrm{M}^{-1}\right)$. Thus, the picture emerging from this study is that anthocyanins (as individual species or non-covalent oligomers) provide a coating of the pectin's surface through the development of very weak interactions (van der Waals contacts, H-bonds).

The quenching of intrinsic protein fluorescence by increasing ligand concentrations is a classical method to probe ligand-protein binding and to extract binding parameters. As anthocyanins typically absorb light at the protein's excitation and emission wavelengths, corrections for these inner-filter effects should be applied [44], which are not systematic [45] and thus lead to discrepancies in $K_{b}$ values as well as in enthalpy and entropy changes. With human serum albumin (HSA), a globular protein, $1: 1$ binding is observed with a $K_{\mathrm{b}}$ in the order of $10^{5} \mathrm{M}^{-1}[44,45]$, meaning a moderate affinity. The influence of the $\mathrm{pH}$ (from $\mathrm{pH}=4$ to $\mathrm{pH}=7.4$ ) on the binding strength is very modest [44]. Competition with probes of a known binding site (ibuprofen, warfarin) enables location of the anthocyanin binding site, a hydrophobic pocket lined by positively charged amino-acid residues (Arg, Lys) for possible accommodation of the anionic base [45]. As for the weakly structured salivary proteins, interaction with malvidin-3-glucoside (probed by STD-NMR) was found to be much weaker $\left(K_{\mathrm{b}} \approx 500 \mathrm{M}^{-1}\right)$ and largely $\mathrm{pH}$-independent (same affinity at $\mathrm{pH}=1.0$ and $\mathrm{pH}=3.4$ ), which suggests that the hemiketal and flavylium ions bind with close affinities [46]. Electrospray ionization MS revealed the formation of soluble aggregates involving 2-6 anthocyanin units and 1-4 peptides (proline-rich proteins or histatin). STD-NMR was also used to investigate the binding of keracyanin (cyanidin 3-rutinoside) to wheat flour gliadins at $\mathrm{pH}=2.5$ [47]. Protons $\mathrm{C} 2^{\prime}-\mathrm{H}, \mathrm{C} 5^{\prime}-\mathrm{H}, \mathrm{C} 6-\mathrm{H}$ and $\mathrm{C} 8-\mathrm{H}$ appear to be primarily involved in the binding. At this low $\mathrm{pH}$, the corresponding aglycone (cyanidin) is stable and can be also investigated. Its affinity for gliadins appears higher based on the strong shielding of its proton signals when gliadins are added (confirmed by the large retention of cyanidin in the centrifugation pellet: up to $80 \%$ vs. only $8 \%$ for keracyanin). However, STP-NMR did not point protons specifically involved in the interaction. Cyanidin 3-glucoside expresses a rather high affinity for sodium caseinate (NaCas) [48]. Two binding sites were identified at $\mathrm{pH}=2$ and $\mathrm{pH}=7$, one of high affinity $\left(K_{\mathrm{b}} \approx 1-7 \times 10^{6} \mathrm{M}^{-1}\right.$ depending on $\mathrm{pH}$ and $\left.\mathrm{T}\right)$ and a second of lower affinity $\left(K_{\mathrm{b}} \approx 2-7 \times 10^{5} \mathrm{M}^{-1}\right)$. For both sites, the binding was found to be exothermic at $\mathrm{pH}=7$ but endothermic at $\mathrm{pH}=2$ and thus is driven by a favorable entropy, which could point to a large contribution of the hydrophobic effect. Interestingly, $\mathrm{NaCl}$ addition gradually cancels cyanidin 3-glucoside-NaCas binding at $\mathrm{pH}=7$ but has no effect at $\mathrm{pH}=2$. In contrast to the high affinity of cyanidin 3-glucoside for NaCas, malvidin 3-glucoside only weakly binds to $\alpha$ - and $\beta$-caseins [49] and to $\beta$-lactoglobulin [50] (1:1 binding with $\left.K_{\mathrm{b}}<10^{3} \mathrm{M}^{-1}\right)$.

Unlike co-pigmentation, the binding of anthocyanins to biopolymers does not trigger spectacular spectral changes. For instance, in the presence of various polysaccharides [51], no change in the wavelength of maximal visible absorption $\left(\lambda_{\max }\right)$ was observed. Interactions of anthocyanins with cellulose, oat bran, and lignin is associated with a weak hypochromic effect, whereas an opposite effect (weak hyperchromism) is observed with highly methylated apple pectins. Sugar beet pectins have 
been shown to promote strong bathochromism in solutions of blackcurrant anthocyanins (cyanidin and delphinidin glycosides), but this effect is due to endogenous iron ions (bound to the polysaccharide) forming blue chelates with the pigments [52]. In agreement with the small spectral changes observed, the binding of anthocyanins to pectin does not significantly affect the thermodynamic constants of the acid-base and hydration equilibria [43]. In other words, all anthocyanin forms (colored or colorless) bind pectin with close affinities. This apparent discrepancy with the STD-NMR data (stronger flavylium-pectin binding) might be due to anthocyanin self-association, which probably is significant in the concentrated solutions used in the STD-NMR experiments. In contrast, the flavylium cation of the pyranoanthocyanin portisin is strongly stabilized by interactions with anionic wood lignosulfates as evidenced by its much weaker acidity in the presence of the polysaccharide ( $\mathrm{p} K_{\mathrm{a} 1}=6.6 \mathrm{vs} .4 .6$ for portisin alone) [53].

\subsection{Anthocyanins in the Excited State}

Although their main function is to absorb visible light and express color, anthocyanins are intrinsically poorly fluorescent with quantum yields typically lower than $4 \times 10^{-3}$ (meaning that less than one photon out of 250 absorbed is actually re-emitted) [54]. Indeed, the fate of anthocyanins after absorption, i.e., once in the excited state, is a difficult question that must be addressed by sophisticated fast techniques, such as time-resolved fluorescence and transient absorption-emission spectroscopies. In the HOMO $\rightarrow$ LUMO transition accompanying the absorption of visible light by the flavylium ion, electron transfer from the B-ring to the A-/C-rings takes place (Figure 16) [55]. In the excited state, the flavylium ion is a strong acid $\left(\mathrm{p} K_{\mathrm{a}}<0\right)$ that transfers a proton to the solvent on a picosecond timescale $(20 \mathrm{ps}$ for pelargonin at $\mathrm{pH}=1)[54,56]$. In the next step, the quinonoid base in the excited state is deactivated by a combination of radiative (fluorescence) and non-radiative (heat) processes and then captures a proton in the ground state to form the ground state flavylium ion. In other words, the quinonoid base is responsible for the (weak) fluorescence observed for anthocyanins even in strongly acidic solution. In the presence of a co-pigment, other mechanisms (Figure 17) supersede the fast flavylium deprotonation observed with free anthocyanins [57] in the following ways: (a) within the complex in the excited state, through ultrafast internal conversion $(<1 \mathrm{ps})$ via a low-energy co-pigment-to-pigment charge transfer state, resulting in static fluorescence quenching; and (b) for the fraction of free anthocyanin, diffusion-controlled electron transfer from the co-pigment to the flavylium ion in the excited state, resulting in dynamic fluorescence quenching. The mechanism of energy dissipation by ultrafast internal conversion has been confirmed for the folded conformation of a cyanidin glycoside acylated by $p$-coumaric acid [58]. In addition, fast energy transfer to the chromophore following absorption of UV light by the acyl residue operates (Figure 17), thereby conferring acylated anthocyanins to have an important role in plant photoprotection.

(A)

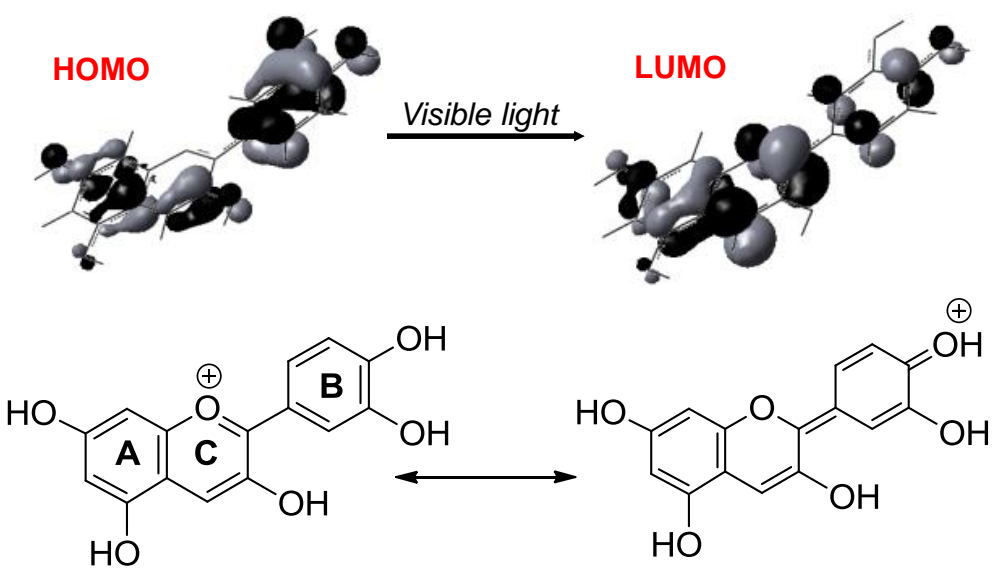

Figure 16. Cont. 
(B)

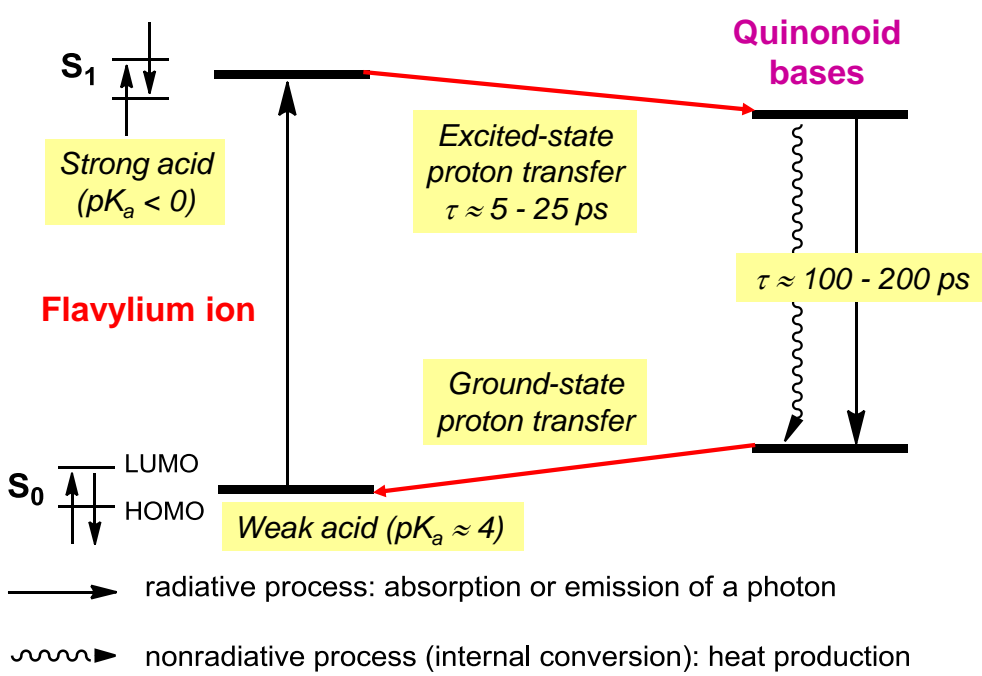

Figure 16. (A) Frontier MOs of the flavylium ion of cyanidin (from reference [55]) and its most representative mesomeric forms in the ground state (left) and first excited state (right). (B) The fate of free anthocyanins in the excited state (from references [54,56]).

\section{Flavylium - CP complex}

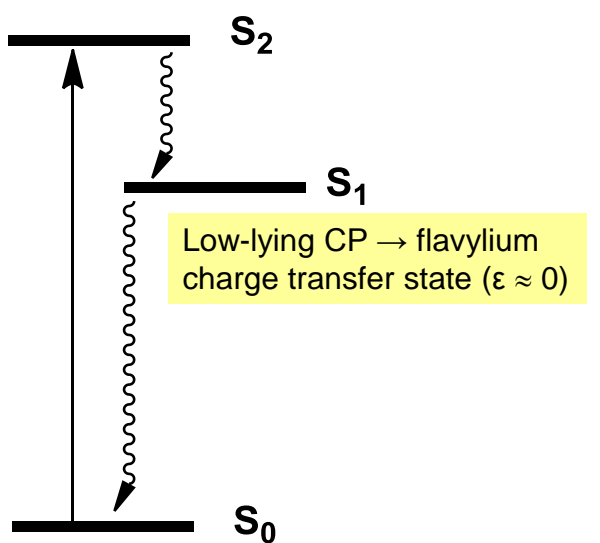

Ultrafast internal conversion, $\tau<1$ ps

(A)

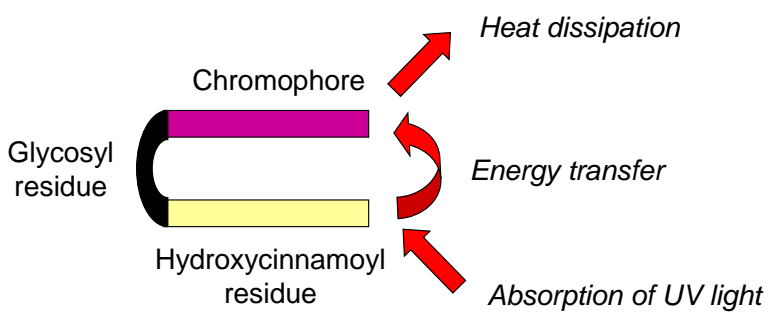

(B)

Figure 17. The influence of co-pigmentation on the fate of anthocyanins in the excited state. (A) Intermolecular co-pigmentation (from reference [57]). (B) Intramolecular co-pigmentation (from reference [58]).

\section{The Importance of Anthocyanin Chemistry in Food and Nutrition}

\subsection{Formulation of Anthocyanins for Food Applications}

Anthocyanin degradation typically occurs during thermal processing and storage. The knowledge on anthocyanin-biopolymer interactions can be applied to devise formulations for improved chemical stability. Degradation studies aimed at demonstrating the protection afforded by biopolymers may be limited to monitoring the color loss under given conditions of $\mathrm{pH}$, temperature, and light exposure. More information is obtained when samples are also acidified to $\mathrm{pH} 1-2$ for quantification of the residual flavylium ions by HPLC or by UV-visible spectroscopy. With this approach, color loss (directly observed at the monitoring $\mathrm{pH}$ ), which combines the reversible water addition and 
irreversible phenomena (hydrolysis, autoxidation), and true anthocyanin loss (irreversible component), can be distinguished.

In the simplest experiments involving modeling beverages, solutions of anthocyanins and soluble biopolymers are heated, and their color or residual anthocyanin concentration is monitored as a function of time. For instance, yeast mannoproteins $(0.5 \% w / w$ for both anthocyanins and mannoproteins) increase the half-life of color loss by a factor of 5.4 in experiments conducted at $\mathrm{pH}=7$ and $\mathrm{T}=80^{\circ} \mathrm{C}$ or $126^{\circ} \mathrm{C}$ (modeling pasteurization or sterilization) [59]. Similarly, the color loss in solutions of purple carrot anthocyanins at $\mathrm{pH}=3.0$ and $\mathrm{T}=40{ }^{\circ} \mathrm{C}$ (in light) was shown to be inhibited by the addition of gum arabic (0.05-5.0\%) with maximal stability observed at $1.5 \%$ ( $50 \%$ color retention after 5 days, vs. $20 \%$ in control) [60]. Similar observations were made with pectins or whey proteins $(1 \%)$, the best result being obtained with heat-denatured whey proteins (70\% color retention after 7 days at $40{ }^{\circ} \mathrm{C}$, vs. $20 \%$ in control) [61]. In these works, fluorescence quenching experiments suggest that color protection involves direct interactions between anthocyanins and proteins (including the glycoprotein of gum arabic). However, the mechanism of protection remains largely unknown. It may be speculated that biopolymers mostly act by providing a more hydrophobic environment to anthocyanins, resulting in slower hydrolysis (despite the weak impact on the hydration equilibrium itself, see Section 2.5.2) and/or by scavenging transition metal traces acting as initiators/catalysts of anthocyanin autoxidation.

A more sophisticated approach consists of preparing solid micro- or nanoparticles as delivery systems for anthocyanins. For instance, nanoparticles of whey proteins and beet pectin can be loaded with anthocyanin extracts with a higher efficiency (55\%) when anthocyanins are added prior nanoparticle formation [62]. However, when dispersed in $\mathrm{pH} 4$ solution, these nanoparticles do not show improved color stability. Particles of chitosan and carboxymethylchitosan (CMC) loaded with anthocyanins (size $\approx 200 \mathrm{~nm}$, encapsulation efficiencies ranging from 16 to $44 \%$ depending on the $\mathrm{CMC} /$ chitosan proportions) can be simply prepared by mixing at $\mathrm{pH}=5-6$ followed by centrifugation [63]. The thermal stability of encapsulated anthocyanins was shown to greatly improve: $12 \%$ degradation after 3 days at $40{ }^{\circ} \mathrm{C}$, vs. $90 \%$ in the control (no particles). Similar protection was observed in samples exposed to white light for 10 days ( $-20 \%$ vs. $-80 \%)$. Sulfonylated polysaccharides, such as dextran sulfate and carrageenans, can also be used to encapsulate bilberry anthocyanins from acidic solutions $(\mathrm{pH} \approx 3)$ with high efficiency and improved stability $[64,65]$. The binding of isotherms and HPLC analysis showed that the binding is selective of anthocyanins (the other phenols remaining in solution) and is stronger when the sulfonylation degree is higher. These data strongly suggest that the encapsulation is driven by ionic flavylium-sulfate interactions. Interestingly, the nanoparticles are gradually dissociated under near neutral conditions modeling the small intestine, which is desirable for subsequent intestinal absorption. Combining chitosan and cellulose nanocrystals at pH 2-3 also allows the formation of nanoparticles with high affinity for anthocyanins (up to $94 \%$ encapsulation) [66]. When cellulose is replaced by sodium tripolyphosphate, a reticulating agent for the polycationic chitosan chain, gel microcapsules (size $\approx 34 \mu \mathrm{m}$, encapsulation yield $\approx 33 \%$ ) are formed. Finally, large hydrogel particles (size $\approx 2-3 \mathrm{~mm}$ ) combining alginate and pectin can be used for encapsulation of anthocyanin-rich extracts under acidic conditions $(\mathrm{pH}=1-3)$, and they are released upon dissolution at higher $\mathrm{pH}$ [67]. When exposed to white light, the half-life values of anthocyanins in hydrogel, hydrogel particles dispersed in pH 3 solution, and in a control solution ( $\mathrm{pH}=3$ ) were $630 \mathrm{~h}, 277 \mathrm{~h}$, and $58 \mathrm{~h}$, respectively.

Interestingly, anthocyanin-rich blackcurrant extracts can be incorporated into bread [68]. Replacing wheat flour by a mixture of gluten and starch led to markedly decreased anthocyanin concentrations (especially, for delphinidin glycosides, which are most sensitive to oxidation). This suggests that other flour proteins (e.g., albumins, globulins) and non-starch polysaccharides (e.g., hemicelluloses, $\beta$-glucans) may be important to provide chemical stability to anthocyanins in such matrices. 


\subsection{The Fate of Anthocyanins in Humans, Consequences on the Possible Effects on Health}

The bioavailability of phenolic compounds has been largely elucidated over the last decades [69]. This knowledge, which is crucial to the interpretation of the possible effects on health, encompasses the bioaccessibility (the release of phenols from the food matrix during digestion), intestinal absorption, metabolism, transport, distribution to tissues, and excretion of dietary phenols and their metabolites. Anthocyanins have emerged as poorly bioavailable micronutrients as judged from the low concentrations (generally, $<0.1 \mu \mathrm{M}$ ) of native forms (mostly, anthocyanidin glucosides) and anthocyanidin conjugates detected in the general blood circulation $[70,71]$. These derivatives are formed in the small intestine after enzymatic hydrolysis by membrane-bound lactate phlorizin hydrolase or by cytosolic $\beta$-glucosidase, and subsequent conjugation by O-glucuronidation, $\mathrm{O}$-methylation, and/or $\mathrm{O}$-sulfonylation. The detection of native forms in the blood circulation is not equivalent to other flavonoid glucosides and could be due to partial absorption from the stomach. This early absorption has been demonstrated in cell and animal models [72-74] and has been proposed to involve the organic anion transporter bilitranslocase in the gastric epithelium [72].

Most importantly, recent investigations, in particular using ${ }^{13}$ C-labelled compounds [3], have shown that the bulk of the ingested amount of anthocyanins is actually converted into simple phenolic compounds (Table 2), as a consequence of (a) the chemical instability (under near neutral conditions) of anthocyanins and, especially, of anthocyanidins [24] and (b) the extensive catabolism by the colonic microbiota of the fraction reaching the large intestine. These simple metabolites, which themselves can be further conjugated by intestinal and hepatic enzymes, have been found in the blood circulation in much higher concentration than anthocyanidin derivatives [3,75].

Table 2. Serum pharmacokinetic profiles of cyanidin 3-glucoside (C3G) and its metabolites in humans after the consumption of $500 \mathrm{mg}{ }^{13} \mathrm{C}$-labelled C3G. From reference [3] (in red is the reference compound and its most abundant metabolites).

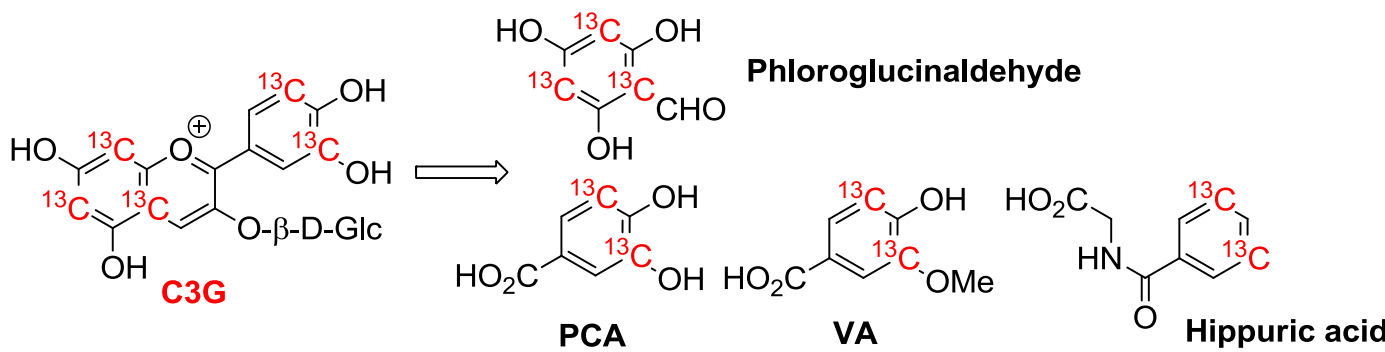

\begin{tabular}{cccccc}
\hline Compound & $\boldsymbol{n}$ & $\boldsymbol{C}_{\mathbf{m a x}} / \mathbf{n M}$ & $\boldsymbol{t}_{\mathbf{m a x}} / \mathbf{h}$ & $\boldsymbol{t}_{\mathbf{1 / 2}} / \mathbf{h}$ & $\mathbf{A U C}_{\mathbf{0 - 4 8}} / \mathbf{n M ~ h}$ \\
\hline Cyanidin-3-glucoside (C3G) & 5 & $141( \pm 70)$ & $1.8( \pm 0.2)$ & 0.4 & $279( \pm 170)$ \\
Protocatechuic acid (PCA) & 8 & $146( \pm 74)$ & $3.3( \pm 0.7)$ & $9.9( \pm 3.4)$ & $1377( \pm 760)$ \\
Phloroglucinaldehyde & 4 & $582( \pm 536)$ & $2.8( \pm 1.1)$ & nd & $7882( \pm 7768)$ \\
PCA-sulfates & 8 & $157( \pm 116)$ & $11.4( \pm 3.8)$ & $31.9( \pm 19.1)$ & $1180( \pm 349)$ \\
Vanillic acid (VA) & 2 & $1845( \pm 838)$ & $12.5( \pm 11.5)$ & 6.4 & $23319( \pm 20650)$ \\
VA-sulfates & 4 & $430( \pm 299)$ & $30.1( \pm 11.4)$ & nd & $10689( \pm 7751)$ \\
Ferulic acid & 7 & $827( \pm 371)$ & $8.2( \pm 4.1)$ & $21.4( \pm 7.8)$ & $17422( \pm 11054)$ \\
Hippuric acid & 8 & $1962( \pm 1389)$ & $15.7( \pm 4.1)$ & $95.6( \pm 77.8)$ & $46568( \pm 30311)$ \\
\hline
\end{tabular}

In agreement with the strong in vivo catabolism of anthocyanins, in vitro digestion models have shown that whereas anthocyanins are readily released into the acidic gastric compartment and relatively stable, they undergo substantial degradation in the near neutral upper intestinal compartment, possibly because of autoxidation [76,77]. However, this chemical instability could be overestimated in in vitro models, as the $\mathrm{O}_{2}$ content is higher than under real physiological conditions. As a striking example, protocatechuic acid (PCA, 3,4-dihydroxybenzoic acid), recovered in blood and fecal samples, was shown to represent more than $70 \%$ of the ingested dose of the cyanidin $O$-glucosides 
from blood orange juice [75]. Interestingly, PCA can be formed by chemical oxidative degradation of anthocyanins and anthocyanidins (Figures 8-10). However, it must be noted that anthocyanins bearing an electron-rich B-ring (e.g., cyanidin and delphinidin glycosides) must be much more prone to oxidative degradation than, for instance, pelargonidin derivatives [78], which indeed could be detected in higher concentrations $(0.2-0.3 \mu \mathrm{M})$ in the blood [79].

In the digestive tract, anthocyanins may also modulate the digestion and uptake of nutrients by interacting with intestinal $\alpha$-glucosidase [80]. They could, as well, attenuate oxidative stress in the digestive tract, for instance, by inhibiting the peroxidation of dietary lipids induced by heme iron $[29,81]$. After intestinal absorption, anthocyanin derivatives are probably transported in the blood in moderate association with serum albumin [45] before distribution to tissues, which, again, could involve bilitranslocase, as evidenced in the kidneys of rats [82].

Most importantly, it must be kept in mind that the degradation products of anthocyanins, which are formed in the digestive tract and are generally much more abundant than the residual anthocyanidin derivatives, could mediate most of the potential health effects of anthocyanins $[83,84]$, which remains intriguing given their chemical simplicity [3] (Table 2). However, redox-active compounds, such as PCA, could indeed participate in regulating the expression of genes associated with transcription factors susceptible to redox activation. Such mechanisms could, at least partly, underline the induction of antioxidant defense via the Nrf2 pathway and the reduction of inflammation via NF-KB inhibition observed in cells and in rodents with cyanidin derivatives [85] or PCA itself [86].

Author Contributions: O.D. and J.-A.F. analyzed the literature and wrote the paper.

Funding: This research received no external funding.

Conflicts of Interest: The authors declare no conflict of interest.

\section{References}

1. Pina, F; Melo, M.J.; Laia, C.A.T.; Parola, A.J.; Lima, J.C. Chemistry and applications of flavylium compounds: A handful of colours. Chem. Soc. Rev. 2012, 41, 869-908. [CrossRef] [PubMed]

2. Pina, F. Chemical applications of anthocyanins and related compounds. A source of bioinspiration. J. Agric. Food Chem. 2014, 62, 6885-6897. [CrossRef] [PubMed]

3. De Ferrars, R.M.; Czank, C.; Zhang, Q.; Botting, N.P.; Kroon, P.A.; Cassidy, A.; Kay, C.D. The pharmacokinetics of anthocyanins and their metabolites in humans. Br. J. Pharmacol. 2014, 171, 3268-3282. [CrossRef] [PubMed]

4. Nave, F.; Petrov, V.; Pina, F.; Teixeira, N.; Mateus, N.; de Freitas, V. Thermodynamic and kinetic properties of a red wine pigment: Catechin-(4,8)-malvidin-3-O-glucoside. J. Phys. Chem. B 2010, 114, 13487-13496. [CrossRef] [PubMed]

5. Moloney, M.; Robbins, R.J.; Collins, T.M.; Kondo, T.; Yoshida, K.; Dangles, O. Red cabbage anthocyanins: The influence of D-glucose acylation by hydroxycinnamic acids on their structural transformations in acidic to mildly alkaline conditions and on the resulting color. Dyes Pigment. 2018, 158, 342-352. [CrossRef]

6. Berké, B.; Chèze, C.; Vercauteren, J.; Deffieux, G. Bisulfite addition to anthocyanins: Revisited structures of colourless adducts. Tetrahedron Lett. 1998, 39, 5771-5774. [CrossRef]

7. Fulcrand, H.; Dueñas, M.; Salas, E.; Cheynier, V. Phenolic reactions during winemaking and aging. Am. J. Enol. Vitic. 2006, 57, 289-297.

8. Oliveira, J.; Mateus, N.; de Freitas, V. Previous and recent advances in pyranoanthocyanins equilibria in aqueous solution. Dyes Pigment. 2014, 100, 190-200. [CrossRef]

9. Vallverdú-Queralt, A.; Meudec, E.; Ferreira-Lima, N.; Sommerer, N.; Dangles, O.; Cheynier, V.; Guernevé, C.L. A comprehensive investigation of guaiacyl-pyranoanthocyanin synthesis by one-/two-dimensional NMR and UPLC-DAD-ESI-MSn. Food Chem. 2016, 199, 902-910. [CrossRef] [PubMed]

10. Oliveira, J.; Fernandes, V.; Miranda, C.; Santos-Buelga, C.; Silva, A.; de Freitas, V.; Mateus, N. Color properties of four cyanidin-pyruvic acid adducts. J. Agric. Food Chem. 2006, 54, 6894-6903. [CrossRef] [PubMed] 
11. Cruz, L.; Petrov, V.; Teixeira, N.; Mateus, N.; Pina, F.; Freitas, V.D. Establishment of the chemical equilibria of different types of pyranoanthocyanins in Aqueous solutions: Evidence for the formation of aggregation in pyranomalvidin-3-O-coumaroylglucoside-(+)-catechin. J. Phys. Chem. B 2010, 114, 13232-13240. [CrossRef] [PubMed]

12. Vallverdú-Queralt, A.; Biler, M.; Meudec, E.; Guernevé, C.L.; Vernhet, A.; Mazauric, J.-P.; Legras, J.-L.; Loonis, M.; Trouillas, P.; Cheynier, V.; et al. p-Hydroxyphenyl-pyranoanthocyanins: An experimental and theoretical investigation of their acid-Base properties and molecular interactions. Int. J. Mol. Sci. 2016, 17, 1842. [CrossRef] [PubMed]

13. Dueñas, M.; Fulcrand, H.; Cheynier, V. Formation of anthocyanin-flavanol adducts in model solutions. Anal. Chim. Acta 2006, 563, 15-25. [CrossRef]

14. Lee, D.F.; Swinny, E.E.; Jones, G.P. NMR identification of ethyl-linked anthocyanin-flavanol pigments formed in model wine ferments. Tetrahedron Lett. 2004, 45, 1671-1674. [CrossRef]

15. Li, L.; Zhang, M.; Zhang, S.; Cui, Y.; Sun, B. Preparation and antioxidant activity of ethyl-linked anthocyanin-flavanol pigments from model wine solutions. Molecules 2018, 23, 1066. [CrossRef] [PubMed]

16. Vallverdú-Queralt, A.; Meudec, E.; Eder, M.; Lamuela-Raventos, R.M.; Sommerer, N.; Cheynier, V. The hidden face of wine polyphenol polymerization highlighted by high-resolution mass spectrometry. ChemistryOpen 2017, 6, 336-339. [CrossRef] [PubMed]

17. Salas, E.; Fulcrand, H.; Meudec, E.; Cheynier, V. Reactions of anthocyanins and tannins in model solutions. J. Agric. Food Chem. 2003, 51, 7951-7961. [CrossRef] [PubMed]

18. Dueñas, M.; Salas, E.; Cheynier, V.; Dangles, O.; Fulcrand, H. UV-visible spectroscopic investigation of the 8,8-methylmethine catechin-malvidin 3-glucoside pigments in aqueous solution: Structural transformations and molecular complexation with chlorogenic acid. J. Agric. Food Chem. 2006, 54, 189-196. [CrossRef] [PubMed]

19. Quideau, S.; Jourdes, M.; Lefeuvre, D.; Montaudon, D.; Saucier, C.; Glories, Y.; Pardon, P.; Pourquier, P. The chemistry of wine polyphenolic C-glycosidic ellagitannins targeting human topoisomerase II. Chem. A Eur. J. 2005, 11, 6503-6513. [CrossRef] [PubMed]

20. Chassaing, S.; Lefeuvre, D.; Jacquet, R.; Jourdes, M.; Ducasse, L.; Galland, S.; Grelard, A.; Saucier, C.; Teissedre, P.-L.; Dangles, O.; et al. Physicochemical studies of new anthocyano-ellagitannin hybrid pigments: About the origin of the influence of oak C-glycosidic ellagitannins on wine color. Eur. J. Org. Chem. 2010, 55-63. [CrossRef]

21. Oliveira, J.; da Silva, M.A.; Jorge Parola, A.; Mateus, N.; Brás, N.F.; Ramos, M.J.; de Freitas, V. Structural characterization of a A-type linked trimeric anthocyanin derived pigment occurring in a young Port wine. Food Chem. 2013, 141, 1987-1996. [CrossRef] [PubMed]

22. Geera, B.; Ojwang, L.O.; Awika, J.M. New highly stable dimeric 3-deoxyanthocyanidin pigments from sorghum bicolor leaf sheath. J. Food Sci. 2012, 77, C566-C572. [CrossRef] [PubMed]

23. Sarni-Manchado, P.; Cheynier, V.; Moutounet, M. Reactions of polyphenoloxidase generated caftaric acid o-quinone with malvidin 3-O-glucoside. Phytochemistry 1997, 45, 1365-1369. [CrossRef]

24. Fleschhut, J.; Kratzer, F.; Rechkemmer, G.; Kulling, S.E. Stability and biotransformation of various dietary anthocyanins in vitro. Eur. J. Nutr. 2006, 45, 7-18. [CrossRef] [PubMed]

25. Cabrita, L.; Petrov, V.; Pina, F. On the thermal degradation of anthocyanidins: Cyanidin. RSC Adv. 2014, 4, 18939-18944. [CrossRef]

26. Lopes, P.; Richard, T.; Saucier, C.; Teissedre, P.-L.; Monti, J.-P.; Glories, Y. Anthocyanone a: A quinone methide derivative resulting from malvidin 3-O-glucoside degradation. J. Agric. Food Chem. 2007, 55, 2698-2704. [CrossRef] [PubMed]

27. Sadilova, E.; Carle, R.; Stintzing, F.C. Thermal degradation of anthocyanins and its impact on color and in vitro antioxidant capacity. Mol. Nutr. Food Res. 2007, 51, 1461-1471. [CrossRef] [PubMed]

28. Kähkönen, M.P.; Heinonen, M. Antioxidant activity of anthocyanins and their aglycons. J. Agric. Food Chem. 2003, 51, 628-633. [CrossRef] [PubMed]

29. Goupy, P.; Bautista-Ortin, A.-B.; Fulcrand, H.; Dangles, O. Antioxidant activity of wine pigments derived from anthocyanins: Hydrogen transfer reactions to the DPPH radical and inhibition of the heme-induced peroxidation of linoleic acid. J. Agric. Food Chem. 2009, 57, 5762-5770. [CrossRef] [PubMed] 
30. Achat, S.; Rakotomanomana, N.; Madani, K.; Dangles, O. Antioxidant activity of olive phenols and other dietary phenols in model gastric conditions: Scavenging of the free radical DPPH and inhibition of the haem-induced peroxidation of linoleic acid. Food Chem. 2016, 213, 135-142. [CrossRef] [PubMed]

31. Matera, R.; Gabbanini, S.; Berretti, S.; Amorati, R.; De Nicola, G.R.; Iori, R.; Valgimigli, L. Acylated anthocyanins from sprouts of Raphanus sativus cv. Sango: Isolation, structure elucidation and antioxidant activity. Food Chem. 2015, 166, 397-406. [CrossRef] [PubMed]

32. Trouillas, P.; Sancho-García, J.C.; De Freitas, V.; Gierschner, J.; Otyepka, M.; Dangles, O. Stabilizing and modulating color by copigmentation: Insights from theory and experiment. Chem. Rev. 2016, 116, 4937-4982. [CrossRef] [PubMed]

33. Mori, M.; Miki, N.; Ito, D.; Kondo, T.; Yoshida, K. Structure of tecophilin, a tri-caffeoylanthocyanin from the blue petals of Tecophilaea cyanocrocus, and the mechanism of blue color development. Tetrahedron 2014, 70, 8657-8664. [CrossRef]

34. Yoshida, K.; Mori, M.; Kondo, T. Blue flower color development by anthocyanins: From chemical structure to cell physiology. Nat. Prod. Rep. 2009, 26, 884. [CrossRef] [PubMed]

35. Alluis, B.; Pérol, N.; El hajji, H.; Dangles, O. Water-soluble flavonol (=3-Hydroxy-2-phenyl-4H-1-benzopyran4-one) derivatives: Chemical synthesis, colouring, and antioxidant properties. Helv. Chim. Acta 2000, 83, 428-443. [CrossRef]

36. Dangles, O.; Saito, N.; Brouillard, R. Anthocyanin intramolecular copigment effect. Phytochemistry 1993, 34, 119-124. [CrossRef]

37. Dangles, O.; Saito, N.; Brouillard, R. Kinetic and thermodynamic control of flavylium hydration in the pelargonidin-cinnamic acid complexation. Origin of the extraordinary flower color diversity of Pharbitis nil. J. Am. Chem. Soc. 1993, 115, 3125-3132. [CrossRef]

38. Figueiredo, P.; George, F.; Tatsuzawa, F.; Toki, K.; Saito, N.; Brouillard, R. New features of intramolecular copigmentation byacylated anthocyanins. Phytochemistry 1999, 51, 125-132. [CrossRef]

39. Mora-Soumille, N.; Al Bittar, S.; Rosa, M.; Dangles, O. Analogs of anthocyanins with a $3^{\prime}, 4^{\prime}$-dihydroxy substitution: Synthesis and investigation of their acid-base, hydration, metal binding and hydrogen-donating properties in aqueous solution. Dyes Pigment. 2013, 96, 7-15. [CrossRef]

40. Kondo, T.; Yoshida, K.; Nakagawa, A.; Kawai, T.; Tamura, H.; Goto, T. Structural basis of blue-colour development in flower petals from Commelina communis. Nature 1992, 358, 515-518. [CrossRef]

41. Shiono, M.; Matsugaki, N.; Takeda, K. Phytochemistry: Structure of the blue cornflower pigment. Nature 2005, 436, 791. [CrossRef] [PubMed]

42. Kallam, K.; Appelhagen, I.; Luo, J.; Albert, N.; Zhang, H.; Deroles, S.; Hill, L.; Findlay, K.; Andersen, Ø.M.; Davies, K.; et al. Aromatic decoration determines the formation of anthocyanic vacuolar inclusions. Curr. Biol. 2017, 27, 945-957. [CrossRef] [PubMed]

43. Fernandes, A.; Brás, N.F.; Mateus, N.; de Freitas, V. Understanding the molecular mechanism of anthocyanin binding to pectin. Langmuir 2014, 30, 8516-8527. [CrossRef] [PubMed]

44. Cahyana, Y.; Gordon, M.H. Interaction of anthocyanins with human serum albumin: Influence of $\mathrm{pH}$ and chemical structure on binding. Food Chem. 2013, 141, 2278-2285. [CrossRef] [PubMed]

45. Tang, L.; Zuo, H.; Shu, L. Comparison of the interaction between three anthocyanins and human serum albumins by spectroscopy. J. Lumin. 2014, 153, 54-63. [CrossRef]

46. Ferrer-Gallego, R.; Soares, S.; Mateus, N.; Rivas-Gonzalo, J.; Escribano-Bailón, M.T.; Freitas, V.D. New anthocyanin-human salivary protein complexes. Langmuir 2015, 31, 8392-8401. [CrossRef] [PubMed]

47. Mazzaracchio, P.; Tozzi, S.; Boga, C.; Forlani, L.; Pifferi, P.G.; Barbiroli, G. Interaction between gliadins and anthocyan derivatives. Food Chem. 2011, 129, 1100-1107. [CrossRef] [PubMed]

48. Casanova, F.; Chapeau, A.-L.; Hamon, P.; de Carvalho, A.F.; Croguennec, T.; Bouhallab, S. pH- and ionic strength-dependent interaction between cyanidin-3-O-glucoside and sodium caseinate. Food Chem. 2018, 267, 52-59. [CrossRef] [PubMed]

49. He, Z.; Xu, M.; Zeng, M.; Qin, F.; Chen, J. Interactions of milk $\alpha$ - and $\beta$-casein with malvidin-3-O-glucoside and their effects on the stability of grape skin anthocyanin extracts. Food Chem. 2016, 199, 314-322. [CrossRef] [PubMed]

50. He, Z.; Zhu, H.; Xu, M.; Zeng, M.; Qin, F.; Chen, J. Complexation of bovine $\beta$-lactoglobulin with malvidin-3-O-glucoside and its effect on the stability of grape skin anthocyanin extracts. Food Chem. 2016, 209, 234-240. [CrossRef] [PubMed] 
51. Mazzaracchio, P.; Pifferi, P.; Kindt, M.; Munyaneza, A.; Barbiroli, G. Interactions between anthocyanins and organic food molecules in model systems. Int. J. Food Sci. Technol. 2004, 39, 53-59. [CrossRef]

52. Buchweitz, M.; Carle, R.; Kammerer, D.R. Bathochromic and stabilising effects of sugar beet pectin and an isolated pectic fraction on anthocyanins exhibiting pyrogallol and catechol moieties. Food Chem. 2012, 135, 3010-3019. [CrossRef] [PubMed]

53. Araújo, P.; Basílio, N.; Azevedo, J.; Fernandes, A.; Mateus, N.; Pina, F.; de Freitas, V.; Oliveira, J. Colour modulation of blue anthocyanin-derivatives. Lignosulfonates as a tool to improve the water solubility of natural blue dyes. Dyes Pigment. 2018, 153, 150-159. [CrossRef]

54. Moreira, P.F.; Giestas, L.; Yihwa, C.; Vautier-Giongo, C.; Quina, F.H.; Maçanita, A.L.; Lima, J.C. Ground- and excited-state proton transfer in anthocyanins: From weak acids to superphotoacids. J. Phys. Chem. A 2003, 107, 4203-4210. [CrossRef]

55. Anouar, E.H.; Gierschner, J.; Duroux, J.-L.; Trouillas, P. UV/Visible spectra of natural polyphenols: A time-dependent density functional theory study. Food Chem. 2012, 131, 79-89. [CrossRef]

56. Ferreira da Silva, P.; Lima, J.C.; Quina, F.H.; Maçanita, A.L. Excited-state electron transfer in anthocyanins and related flavylium salts. J. Phys. Chem. A 2004, 108, 10133-10140. [CrossRef]

57. Rodrigues, R.F.; Ferreira da Silva, P.; Shimizu, K.; Freitas, A.A.; Kovalenko, S.A.; Ernsting, N.P.; Quina, F.H.; Maçanita, A. Ultrafast internal conversion in a model anthocyanin-polyphenol complex: Implications for the biological role of anthocyanins in vegetative tissues of plants. Chem. A Eur. J. 2009, 15, 1397-1402. [CrossRef] [PubMed]

58. Ferreira da Silva, P.; Paulo, L.; Barbafina, A.; Elisei, F.; Quina, F.H.; Maçanita, A.L. Photoprotection and the photophysics of acylated anthocyanins. Chem. A Eur. J. 2012, 18, 3736-3744. [CrossRef] [PubMed]

59. Wu, J.; Guan, Y.; Zhong, Q. Yeast mannoproteins improve thermal stability of anthocyanins at $\mathrm{pH} 7.0$. Food Chem. 2015, 172, 121-128. [CrossRef] [PubMed]

60. Chung, C.; Rojanasasithara, T.; Mutilangi, W.; McClements, D.J. Enhancement of colour stability of anthocyanins in model beverages by gum arabic addition. Food Chem. 2016, 201, 14-22. [CrossRef] [PubMed]

61. Chung, C.; Rojanasasithara, T.; Mutilangi, W.; McClements, D.J. Enhanced stability of anthocyanin-based color in model beverage systems through whey protein isolate complexation. Food Res. Int. 2015, 76, 761-768. [CrossRef] [PubMed]

62. Arroyo-Maya, I.J.; McClements, D.J. Biopolymer nanoparticles as potential delivery systems for anthocyanins: Fabrication and properties. Food Res. Int. 2015, 69, 1-8. [CrossRef]

63. Ge, J.; Yue, P.; Chi, J.; Liang, J.; Gao, X. Formation and stability of anthocyanins-loaded nanocomplexes prepared with chitosan hydrochloride and carboxymethyl chitosan. Food Hydrocoll. 2018, 74, $23-31$. [CrossRef]

64. Klimaviciute, R.; Navikaite, V.; Jakstas, V.; Ivanauskas, L. Complexes of dextran sulfate and anthocyanins from Vaccinium myrtillus: Formation and stability. Carbohydr. Polym. 2015, 129, 70-78. [CrossRef] [PubMed]

65. Navikaite, V.; Simanaviciute, D.; Klimaviciute, R.; Jakstas, V.; Ivanauskas, L. Interaction between K- and l-carrageenan and anthocyanins from Vaccinium myrtillus. Carbohydr. Polym. 2016, 148, 36-44. [CrossRef] [PubMed]

66. Wang, W.; Jung, J.; Zhao, Y. Chitosan-cellulose nanocrystal microencapsulation to improve encapsulation efficiency and stability of entrapped fruit anthocyanins. Carbohydr. Polym. 2017, 157, 1246-1253. [CrossRef] [PubMed]

67. Guo, J.; Giusti, M.M.; Kaletunç, G. Encapsulation of purple corn and blueberry extracts in alginate-pectin hydrogel particles: Impact of processing and storage parameters on encapsulation efficiency. Food Res. Int. 2018, 107, 414-422. [CrossRef] [PubMed]

68. Sivam, A.S.; Sun-Waterhouse, D.; Perera, C.O.; Waterhouse, G.I.N. Exploring the interactions between blackcurrant polyphenols, pectin and wheat biopolymers in model breads; a FTIR and HPLC investigation. Food Chem. 2012, 131, 802-810. [CrossRef]

69. Del Rio, D.; Rodriguez-Mateos, A.; Spencer, J.P.E.; Tognolini, M.; Borges, G.; Crozier, A. Dietary (Poly) phenolics in human health: Structures, bioavailability, and evidence of protective effects against chronic diseases. Antioxid. Redox Signal. 2013, 18, 1818-1892. [CrossRef] [PubMed]

70. Kay, C.D. Aspects of anthocyanin absorption, metabolism and pharmacokinetics in humans. Nutr. Res. Rev. 2006, 19, 137-146. [CrossRef] [PubMed] 
71. Manach, C.; Williamson, G.; Morand, C.; Scalbert, A.; Rémésy, C. Bioavailability and bioefficacy of polyphenols in humans. I. Review of 97 bioavailability studies. Am. J. Clin. Nutr. 2005, 81, 230S-242S. [CrossRef] [PubMed]

72. Passamonti, S.; Vrhovsek, U.; Mattivi, F. The interaction of anthocyanins with bilitranslocase. Biochem. Biophys. Res. Commun. 2002, 296, 631-636. [CrossRef]

73. Fernandes, I.; Freitas, V.D.; Reis, C.; Mateus, N. A new approach on the gastric absorption of anthocyanins. Food Funct. 2012, 3, 508-516. [CrossRef] [PubMed]

74. Talavéra, S.; Felgines, C.; Texier, O.; Besson, C.; Lamaison, J.-L.; Rémésy, C. Anthocyanins are efficiently absorbed from the stomach in anesthetized rats. J. Nutr. 2003, 133, 4178-4182. [CrossRef] [PubMed]

75. Vitaglione, P.; Donnarumma, G.; Napolitano, A.; Galvano, F.; Gallo, A.; Scalfi, L.; Fogliano, V. Protocatechuic acid is the major human metabolite of cyanidin-glucosides. J. Nutr. 2007, 137, 2043-2048. [CrossRef] [PubMed]

76. Bouayed, J.; Deußer, H.; Hoffmann, L.; Bohn, T. Bioaccessible and dialysable polyphenols in selected apple varieties following in vitro digestion vs. their native patterns. Food Chem. 2012, 131, 1466-1472. [CrossRef]

77. Tagliazucchi, D.; Verzelloni, E.; Bertolini, D.; Conte, A. In vitro bio-accessibility and antioxidant activity of grape polyphenols. Food Chem. 2010, 120, 599-606. [CrossRef]

78. Woodward, G.; Kroon, P.; Cassidy, A.; Kay, C. Anthocyanin stability and recovery: Implications for the analysis of clinical and experimental samples. J. Agric. Food Chem. 2009, 57, 5271-5278. [CrossRef] [PubMed]

79. Mullen, W.; Edwards, C.A.; Serafini, M.; Crozier, A. Bioavailability of pelargonidin-3-O-glucoside and its metabolites in humans following the ingestion of strawberries with and without cream. J. Agric. Food Chem. 2008, 56, 713-719. [CrossRef] [PubMed]

80. McDougall, G.J.; Fyffe, S.; Dobson, P.; Stewart, D. Anthocyanins from red wine-Their stability under simulated gastrointestinal digestion. Phytochemistry 2005, 66, 2540-2548. [CrossRef] [PubMed]

81. Dangles, O. Antioxidant activity of plant phenols: Chemical mechanisms and biological significance. Curr. Org. Chem. 2012, 16, 1-23. [CrossRef]

82. Vanzo, A.; Terdoslavich, M.; Brandoni, A.; Torres, A.M.; Vrhovsek, U.; Passamonti, S. Uptake of grape anthocyanins into the rat kidney and the involvement of bilitranslocase. Mol. Nutr. Food Res. 2008, 52, 1106-1116. [CrossRef] [PubMed]

83. Tsuda, T. Dietary anthocyanin-rich plants: Biochemical basis and recent progress in health benefits studies. Mol. Nutr. Food Res. 2012, 56, 159-170. [CrossRef] [PubMed]

84. De Pascual-Teresa, S. Molecular mechanisms involved in the cardiovascular and neuroprotective effects of anthocyanins. Arch. Biochem. Biophys. 2014, 559, 68-74. [CrossRef] [PubMed]

85. Hwang, Y.P.; Choi, J.H.; Yun, H.J.; Han, E.H.; Kim, H.G.; Kim, J.Y.; Park, B.H.; Khanal, T.; Choi, J.M.; Chung, Y.C.; et al. Anthocyanins from purple sweet potato attenuate dimethylnitrosamine-induced liver injury in rats by inducing Nrf2-mediated antioxidant enzymes and reducing COX-2 and iNOS expression. Food Chem. Toxicol. 2011, 49, 93-99. [CrossRef] [PubMed]

86. Wang, D.; Wei, X.; Yan, X.; Jin, T.; Ling, W. Protocatechuic acid, a metabolite of anthocyanins, inhibits monocyte adhesion and reduces atherosclerosis in apolipoprotein E-deficient mice. J. Agric. Food Chem. 2010, 58, 12722-12728. [CrossRef] [PubMed]

(c) 2018 by the authors. Licensee MDPI, Basel, Switzerland. This article is an open access article distributed under the terms and conditions of the Creative Commons Attribution (CC BY) license (http://creativecommons.org/licenses/by/4.0/). 